\title{
Percepção térmica em um ambiente com painéis radiantes acoplados a um teto- reservatório
}

\author{
Thermal perception in a room with radiant cooling panels \\ coupled to a roof pond
}

\section{Leandro Carlos Fernandes \\ Eduardo Leite Krüger \\ Wolfgang Motzafi-Haller}

\section{Resumo \\ $\mathbf{T}$}

etos-reservatório (TR) podem colaborar para obtenção de condições térmicas confortáveis, particularmente em edificações térreas.

Possibilitam resfriamento ou aquecimento estrutural e estabilização

das temperaturas superficiais e do ar. Uma alternativa para melhorar

o desempenho do TR é acoplá-lo a painéis radiantes. Atualmente, há escassez de pesquisas enfocando a percepção térmica de usuários em ambientes fechados condicionados por TR. O objetivo desta pesquisa foi verificar, empiricamente, para condições de verão, a percepção térmica de voluntários em um ambiente condicionado por painéis radiantes acoplados a TR. Buscouse também identificar qual modelo adaptativo melhor representaria os votos declarados pelos participantes do estudo. Como parâmetros para análise das percepções térmicas reportadas, adotaram-se o modelo PMV e os modelos para edificações passivas das normas Standard 55 e EN 15251. O experimento ocorreu em uma edificação-teste da Ben-Gurion University of Negev, em Israel. Foram consideradas respostas de 46 voluntários. O ambiente dotado de TR foi percebido como confortável pela maior parte dos voluntários. As respostas subjetivas apresentaram maior concordância com os modelos PMV e da EN 15251 do que com o modelo da ASHRAE.

Palavras-chave: Teto-reservatório. Resfriamento radiante. Resfriamento passivo. Conforto térmico.

${ }^{1}$ Leandro Carlos Fernandes 1 Universidade Federal do Paraná Curitiba - PR - Brasil

${ }^{2}$ Eduardo Leite Krüger 2Universidade Tecnológica Federal do Paraná Curitiba - PR - Brasil

${ }^{3}$ Wolfgang Motzafi-Haller ${ }^{3}$ Ben Gurion University of the Negev Midreshet Ben Gurion - Israel

Recebido em 11/09/19 Aceito em 07/12/19

\begin{abstract}
Roof ponds $(R P)$ can promote comfortable thermal conditions, particularly in single-storey buildings. They allow structural cooling or heating and the stabilisation of surface and air temperatures. When coupled to radiant panels cooled by the exposed pond, they can further improve their thermal performance. However, there is a lack of research on RP focusing on the thermal perception of users indoors. The main objective of this study was to verify, empirically, under summer conditions, the thermal perceptions of volunteer participants in an indoor environment conditioned by a system composed of radiant panels coupled to a RP. We also sought to identify which adaptive model best represents the thermal votes reported by the study participants. As parameters for analysis of reported thermal votes, the PMV model and the passive building model of ASHRAE Standard 55 and EN-15251 were employed. The experiment took place in a test building at Ben-Gurion

University of Negev, Israel. The sample consisted of 46 volunteer participants. The RP environment was perceived as comfortable by most volunteers. The thermal votes showed more agreement with the PMV and EN 15251 models than with the ASHRAE model.

Keywords: Roof pond. Radiant cooling. Passive cooling. Thermal comfort.
\end{abstract}




\section{Introdução}

Quanto ao condicionamento térmico interno, as edificações podem ser classificadas como ativas (condicionadas mecanicamente) ou passivas (divididas em duas subcategorias: sem dispositivos para aquecimento ou resfriamento passivo; e dotadas de dispositivos para aquecimento e/ou resfriamento passivo (BRAVO; GONZÁLEZ, 2013). Os artifícios para condicionamento térmico, ativos ou passivos, atuam diferentemente sobre as variáveis ambientais internas, podendo resultar em sensações térmicas distintas.

Dentre os artifícios para condicionamento passivo, citam-se os tetos-reservatório (TR). O TR é indicado principalmente para edificações com poucos pavimentos, pois atua mais intensamente sobre os ambientes imediatamente abaixo do reservatório. Proporciona resfriamento ou aquecimento estrutural e estabilização das temperaturas superficiais e do ar. Em alguns casos, é efetivo durante todo o ano, reduzindo ou eliminando a demanda por sistemas ativos (SHARIFI; YAMAGATA, 2015).

As primeiras revisões bibliográficas a respeito do TR apresentaram poucos títulos e enfocaram basicamente reservatórios de concreto (TIWARI; KUMAR; SODHA, 1982; GIVONI, 2011). No entanto, revisões posteriores apresentaram TR de diversas configurações e de diferentes materiais, indicando aumento do interesse pelo tema (SPANAKI; TSOUTSOS; KOLOKOTSA, 2011; SHARIFI; YAMAGATA, 2015).

Dentre as novas abordagens, busca-se potencializar o resfriamento evaporativo e explorar o resfriamento radiante utilizando reservatórios metálicos (GONZÁLEZ-CRUZ, 1997; TÉPOX; GONZÁLEZ-CRUZ; MATA, 2008; GONZÁLEZ-CRUZ; GONZÁLEZ-GARCIA, 2013) em vez de reservatórios de concreto, predominantes até então. Devido à maior condutividade térmica dos reservatórios metálicos (GONZÁLEZCRUZ, 1997), ocorre redução da diferença entre as temperaturas da água do reservatório e do ar do ambiente abaixo, comparativamente ao uso de reservatórios de concreto (CHÁVEZ; GIVONI; MUNDET, 2007).

Recentemente, utilizando equações preditivas, avaliou-se a aplicabilidade do TR metálico em 411 cidades brasileiras. Os resultados indicaram que o uso dessa estratégia seria efetivo na redução das médias das temperaturas internas na maioria dos locais. Obtiveram-se reduções entre $-0,8{ }^{\circ} \mathrm{C}$ e $-2,5{ }^{\circ} \mathrm{C}$ (GONZÁLEZCRUZ; KRÜGER; GIORDANO, 2014).

Também foi analisada a aplicabilidade do TR metálicos aos climas das regiões de Florianópolis e Curitiba utilizando células-teste. Nessas pesquisas, as médias das temperaturas internas do ar também apresentaram redução de aproximadamente $2{ }^{\circ} \mathrm{C}$ em comparação com as médias externas (GONZÁLEZ-CRUZ; KRÜGER; GIORDANO, 2014; KRÜGER; FERNANDES; LANGE, 2016; KRÜGER et al., 2016).

Uma alternativa para melhorar o desempenho dos reservatórios de concreto é acoplá-los a sistemas de resfriamento radiante tendo água como fluído, reduzindo as perdas térmicas (LI et al., 2015). Há evidências de que sistemas de resfriamento radiante podem propiciar condições de conforto iguais ou melhores que sistemas de ar condicionado convencionais (KARMANN; SCHIAVON; BAUMAN, 2017). Testes em uma edificação experimental dotada de painéis de resfriamento radiante mostraram que dois terços do resfriamento de verão ocorreram por radiação e apenas um terço por convecção (MIRIEL; SERRES; TROMBE, 2002). Segundo a ASHRAE, em sistemas de aquecimento e resfriamento radiante, a transferência de calor radiante cobre mais de $50 \%$ das trocas de calor dentro do espaço condicionado (AMERICAN..., 2012).

No entanto, ainda há carência de estudos de campo, especialmente envolvendo a percepção térmica de usuários (MUSTAKALLIO et al., 2017). Os estudos sobre resfriamento radiante e resfriamento evaporativo ainda enfocam principalmente a otimização e o desempenho dos sistemas (SHARIFI; YAMAGATA, 2015).

Imanari, Omori e Bogaki (1999) compararam as percepções térmicas de usuários submetidos a dois modos de resfriamento de uma sala de reuniões:

(a) com um painel radiante suspenso no teto; $\mathrm{e}$

(b) com uma unidade de ar-condicionado.

O resfriamento radiante gerou uma porcentagem maior de votos de conforto, embora as condições térmicas fossem equivalentes. Recentemente, Meggers et al. (2017) apresentaram estudo com voluntários em pavilhão experimental semi-fechado com sistema de resfriamento evaporativo indireto e painéis radiantes (PR) com serpentinas resfriadas. Em um dia de verão, embora as temperaturas internas e externas do ar fossem similares, a maior parte dos participantes estimou temperaturas internas inferiores às externas. No entanto, nenhum dos dois experimentos apresenta TR ou resfriamento estrutural.

336 Fernandes, L. C.; Krüger, E. L.; Motzafi-Haller, W. 
Dada a lacuna apontada, o objetivo geral desta pesquisa foi avaliar a percepção térmica de usuários em um ambiente condicionado por painéis radiantes acoplados a um teto-reservatório. Como objetivo secundário, buscou-se identificar qual modelo adaptativo melhor representa os votos declarados pelos participantes do estudo.

\section{Procedimentos metodológicos}

O experimento, com participação de voluntários e aplicação de questionários, foi conduzido em uma edificação-teste. Neste artigo, é relatada a parte do experimento relativa à percepção térmica na sala equipada com painéis radiantes acoplados ao TR. Também foram realizados estudos abordando condicionamento com ar-condicionado e desempenho térmico, a serem publicados em separado.

\section{Sala utilizada no estudo}

O estudo foi realizado no Campus Sde Boqer, da Ben-Gurion University of the Negev, na Midreshet Ben Gurion, Israel (Latitude 30,8 ${ }^{\circ} \mathrm{N}$, Longitude $34,8^{\circ} \mathrm{L}$ e $478 \mathrm{~m}$ de altitude). O campus está localizado no deserto de Negev (ISRAEL..., 2007). A precipitação média anual local é de 93 mm (ISRAEL..., 2012). O clima apresenta grandes flutuações térmicas diárias e sazonais, ar seco e céu limpo com radiação solar intensa. No verão, a média das temperaturas diárias máximas é $32{ }^{\circ} \mathrm{C}$ e a das mínimas é $17{ }^{\circ} \mathrm{C}$. A radiação global é de $7,7 \mathrm{kWh} / \mathrm{m}^{2}$ por dia durante junho e julho. No inverno, os dias normalmente são ensolarados. A média das temperaturas diárias máximas é $14,9{ }^{\circ} \mathrm{C}$ e a das mínimas é $3,8^{\circ} \mathrm{C}$ (BITAN; RUBIN, $1991^{1}$ apud KRÜGER; GONZÁLEZ-CRUZ; GIVONI, 2010). Na classificação de Köppen-Geiger, a região é uma área de transição entre os climas BWh (das regiões desérticas quentes de baixa latitude e altitude), ao sul, e BSh (das estepes quentes de baixa latitude e altitude), ao norte (KOTTEK et al., 2006; RUBEL et al., 2017). Os meses de junho até setembro, de interesse para este estudo, apresentam altas temperaturas e pouca precipitação.

A sala utilizada faz parte de uma edificação-teste (Figura 1) construída em 1991 (ERELL et al., 1993; ERELL; ETZION, 1999). A edificação possui três salas semelhantes, pintadas de branco e medindo $2,70 \mathrm{~m}$ de largura por 3,5 m de comprimento e 3,05 $\mathrm{m}$ de altura. Todas possuem janelas com esquadrias de PVC na face sul (Figuras 1 e 4), com 1,5 m de largura por 2,22 $\mathrm{m}$ de altura. Essas janelas apresentam vidro fixo em suas partes inferior (placa de vidro com $0,36 \mathrm{~m}$ de altura) e superior (vidro com 0,64 $\mathrm{m}$ de altura) e uma seção central de correr (vidro com $0,98 \mathrm{~m}$ de altura). Os panos de vidro são duplos, com espessura $4 \mathrm{~mm}$ e a câmara de ar com $6 \mathrm{~mm}$. A profundidade do peitoril é de $0,25 \mathrm{~m}$. Durante o experimento, as partes superior e central foram recobertas por persianas externas de PVC branco (Figuras 1, 2 e 4) para reduzir a incidência de radiação solar. As laterais das janelas também dispunham de brises verticais de madeira $(0,9 \mathrm{~m}$ de profundidade por 3,4 $\mathrm{cm}$ de altura).

A sala na extremidade leste da edificação (sala TR), à direita na Figura 2, recebeu o TR em sua cobertura. A sala possuía uma unidade de ar-condicionado, do tipo split. No entanto, durante os experimentos, foi desabilitada a função de resfriamento. $O$ aparelho funcionou apenas no modo ventilação forçada. $O$ acionamento da função ventilação ocorreu para viabilizar a comparação das percepções térmicas dos usuários com as percepções registradas em outra sala, cujos dados não são apresentados neste artigo, na qual foi utilizado resfriamento mecânico (etapa a ser publicada futuramente). O mobiliário da sala ficou restrito a uma mesa de trabalho e uma cadeira. A Figura 3 apresenta os painéis radiantes no teto da sala TR.

\section{Configurações da cobertura}

As diferentes etapas do experimento aqui relatado foram realizadas na mesma sala, indicada na Figura 2. Previamente à aplicação dos questionários, comparou-se o desempenho térmico da configuração original da sala de testes com o desempenho quando com o sistema de resfriamento (painéis radiantes acoplados ao TR). Para isso, tanto a configuração original quanto a configuração experimental foram monitoradas.

${ }^{1}$ BITAN, A.; RUBIN, S. Climatic Atlas of Israel for Physical Planning and Design. Israel Meteorological Service and Ministry of Energy and Infrastructure, 1991. 
Figura 1 - Fachada sul da edificação-teste

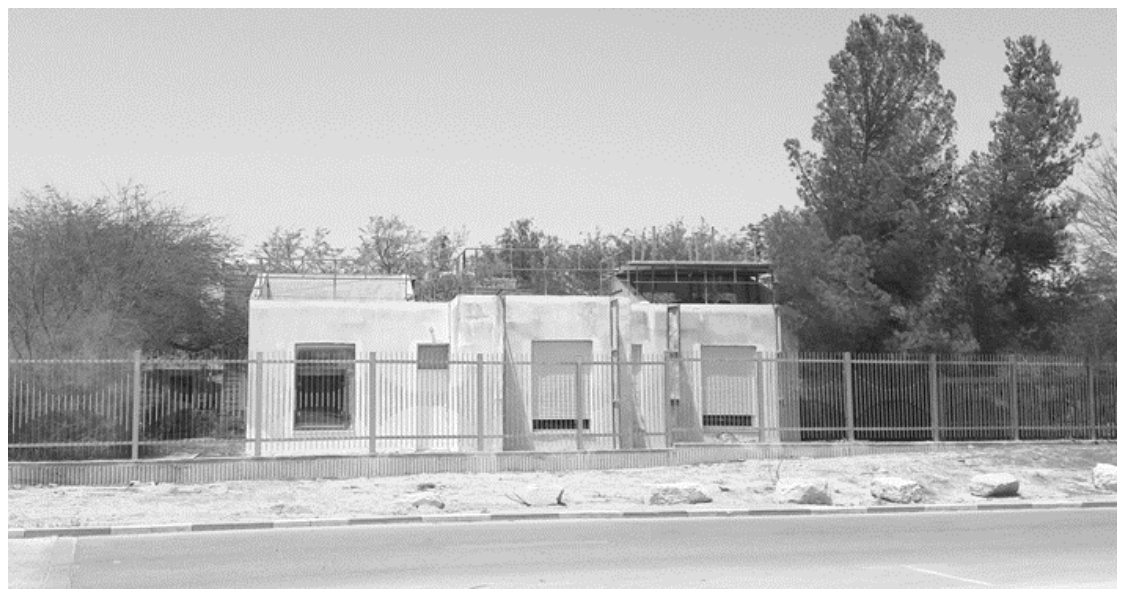

Figura 2 - Planta baixa da edificação-teste

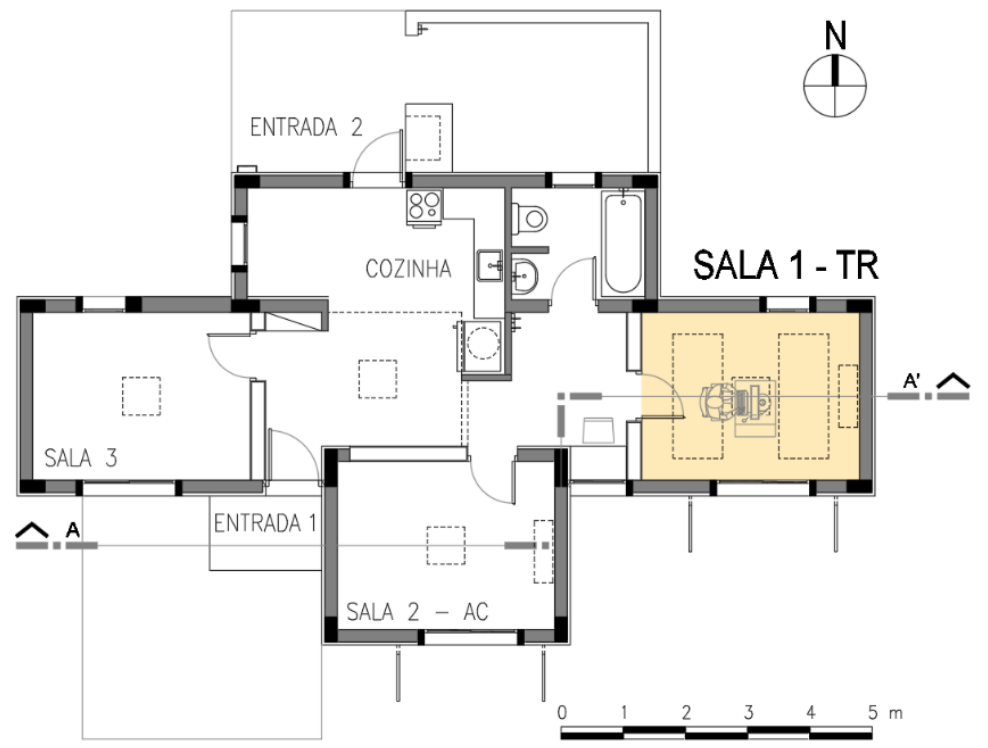

Figura 3 - Teto da sala TR, mostrando os painéis radiantes

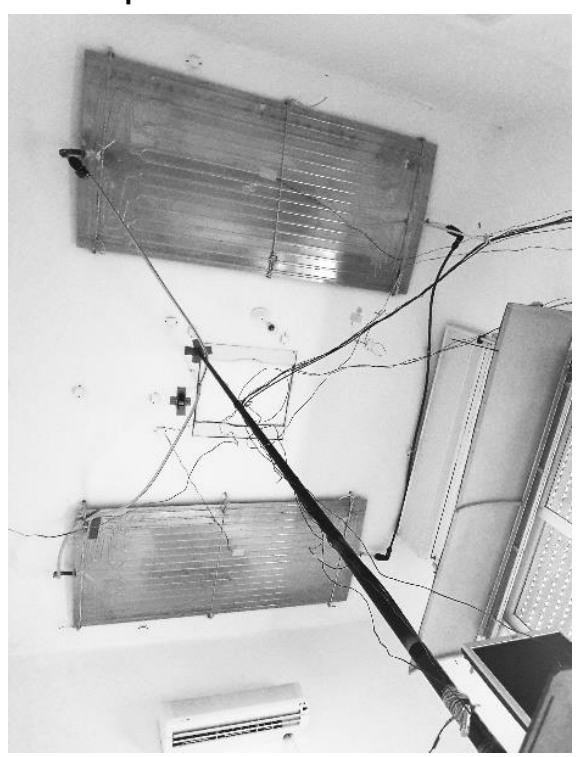

338 Fernandes, L. C.; Krüger, E. L.; Motzafi-Haller, W. 
A configuração original da cobertura era constituída de uma laje de concreto com $10 \mathrm{~cm}$ de espessura, regularizada e impermeabilizada, revestida com $3 \mathrm{~cm}$ de argamassa e pintada de branco. Neste artigo, utilizou-se o monitoramento dessa configuração no período de 16/06/2017 até 24/06/2017, abrangendo 9 dias, para, via método preditivo descrito na subseção Estimativa de temperaturas internas horárias, realizar comparação com a configuração experimental, instalada posteriormente.

Para constituir a configuração experimental, dotada do sistema de resfriamento, realizaram-se acréscimos à configuração original. Sobre toda a área da laje, foi adicionada uma piscina de plástico branco, caracterizando o teto-reservatório (TR). O TR foi preenchido com 755 litros de água, camada com $8,7 \mathrm{~cm}$ de profundidade e $8,64 \mathrm{~m}^{2}$ de superfície. A água evaporada era reposta diariamente, pela manhã. Para sombreamento, $1,5 \mathrm{~m}$ acima da laje, possibilitando livre ventilação, foi instalado um telhado de telhas de PVC branco, com $2 \mathrm{~mm}$ de espessura. Também foi instalada uma bomba d'água, forçando a circulação entre o reservatório e dois painéis radiantes de alumínio com serpentinas, colocados no interior do ambiente de testes, medindo $2,0 \mathrm{~m} \times 0,8 \mathrm{~m}$ cada um $\left(1,6 \mathrm{~m}^{2}\right)$. Sobre a água, foi disposta uma camada flutuante de EPS, constituída de placas medindo $50 \mathrm{~cm} \times 100 \mathrm{~cm} \times 6 \mathrm{~cm}$, cobrindo área de $8,0 \mathrm{~m}^{2}$, restando $0,64 \mathrm{~m}^{2}$ de água exposta à evaporação. Sobre o reservatório e abaixo das telhas, acrescentou-se um sistema de sprays, acionado no período noturno (das $17 \mathrm{~h} 45$ até as $8 \mathrm{~h} 30$ do dia seguinte). Os sprays borrifavam água, formando cones d'água com abertura de aproximadamente $45^{\circ}$. Neste artigo, considerou-se o monitoramento dessa configuração no período de 31/07/2017 até 21/09/2017, abrangendo 22 dias (Figura 4).

\section{Monitoramento}

Os dados relativos às condições externas foram obtidos da estação meteorológica do campus, instalada 800 $\mathrm{m}$ ao norte da edificação-teste. Foram fornecidas as variáveis: temperatura de bulbo seco $\left(T_{a}\right)$, velocidade do $\operatorname{ar}\left(v_{a}\right)$, radiação solar global $(\mathrm{R})$ e umidade relativa do ar (UR).

A instalação dos equipamentos e sensores na edificação-teste (Figuras 5 e 6) seguiu orientações da norma ISO 7726 (INTERNATIONAL..., 1998). Os dados foram registrados em uma central data logger (Campbell Scientific Datalogger CR23X), à qual foi conectada uma interface (Campbell Scientific Multiplexer AM-32) para ampliar o número de entradas. Na sala TR, foram conectados à interface 15 sensores de temperatura (termopares Tipo $\mathrm{T}$, com precisão de $\pm 0,2{ }^{\circ} \mathrm{C}$ ):

(c) 4 medindo temperatura do ar $\left(T_{a}\right)$ em diferentes alturas $(0,1 \mathrm{~m}$, tornozelo;

(d) 0,6 m, abdômen;

(e) 1,1 m, cabeça; e

(f) 2,8 m, próximo ao teto), 1 medindo a temperatura de globo $\left(T_{g}\right)$ a $0,6 \mathrm{~m}$ de altura e 10 medindo temperaturas superficiais $\left(T_{S}\right)$ (6 para teto, piso e paredes, 2 para os painéis radiantes e 2 para os vidros da janela principal).

Figura 4 - Vista frontal e corte AA' - Sala TR
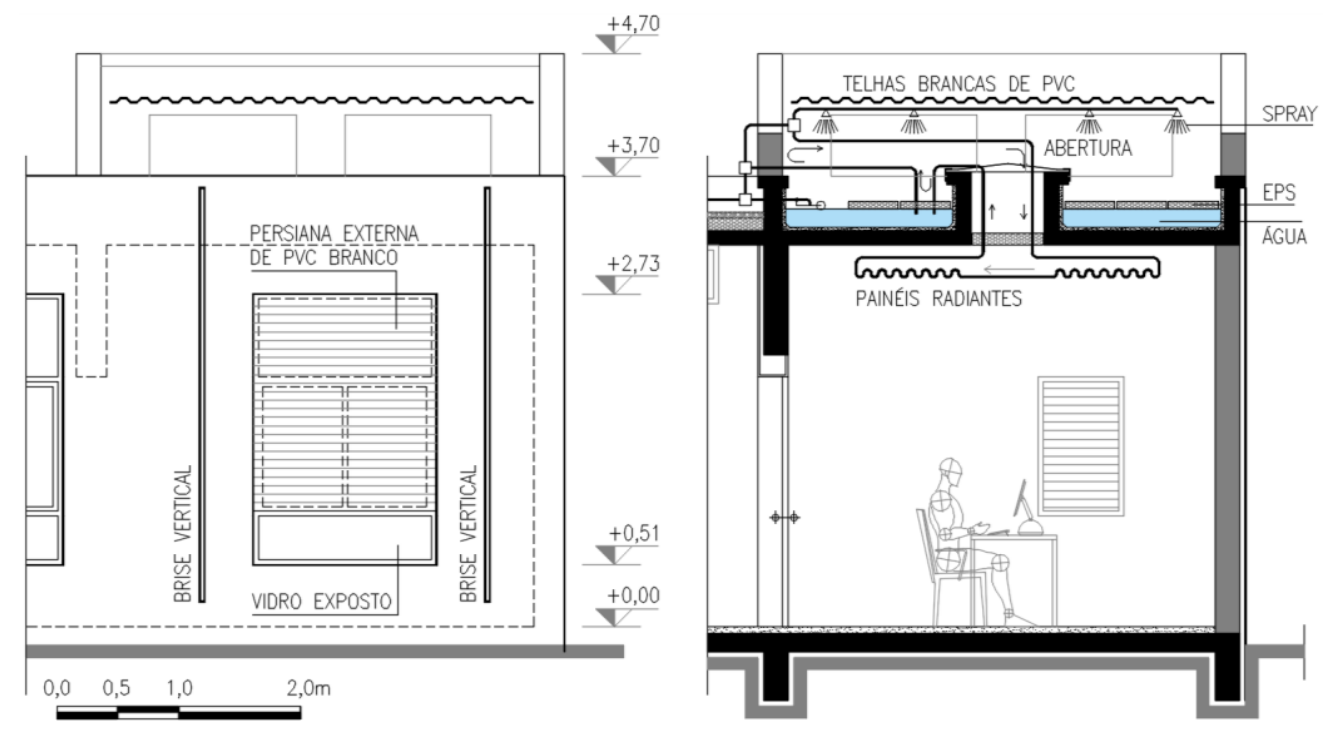
Figura 5 - Planta baixa com as posições dos sensores

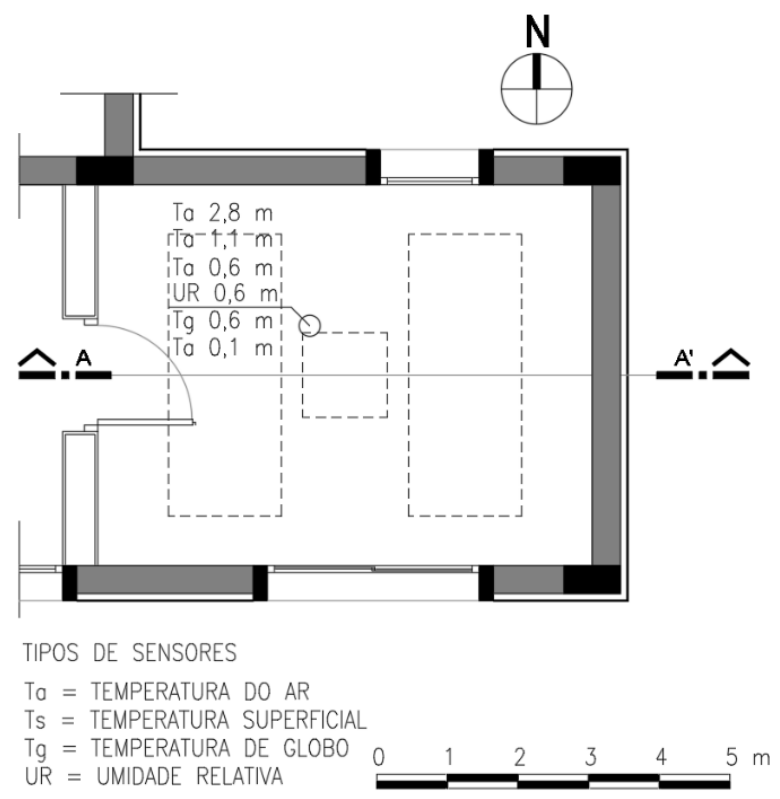

Figura 6 - Corte com as posições dos sensores

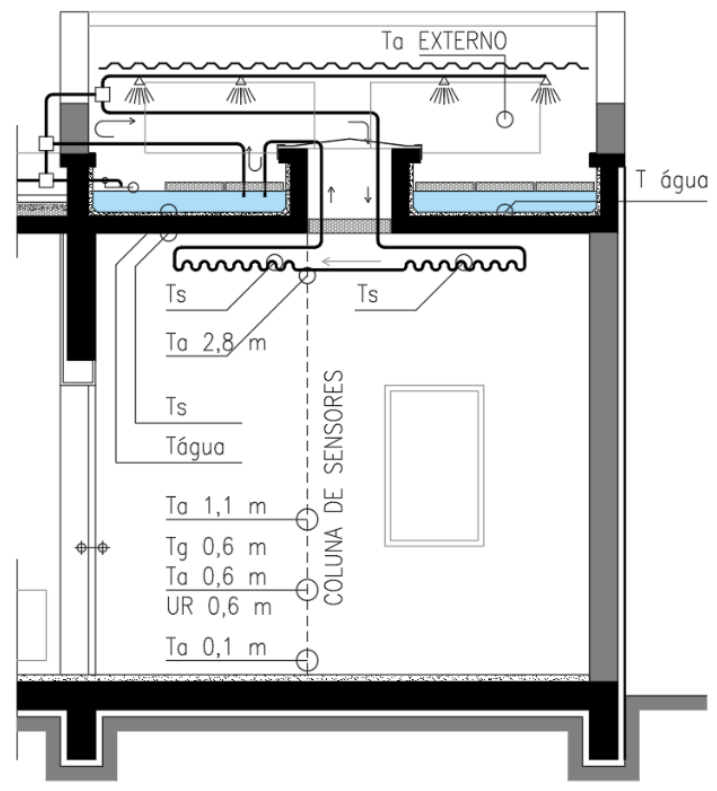

Sobre a cobertura, foram instalados 3 sensores Tipo T: 2 para monitorar a temperatura da água e 1 para medir a $T_{a}$. A sala também recebeu um sensor de temperatura $\left(T_{a}\right)$ e umidade relativa (UR) (modelo Vaisala HMP-60 Temperature/Relative Humidity, com precisão de $\pm 0,5{ }^{\circ} \mathrm{C} / \pm 3 \%$ UR) instalado a $0,6 \mathrm{~m}$ de altura. As leituras ocorreram a cada 30 segundos e foram gravadas as médias para cada 10 minutos. A $v_{a}$ interna foi medida com anemômetro portátil de fio quente (Kurz Portable Air Velocity Meter Series-441, precisão de $\pm 0,05 \mathrm{~m} / \mathrm{s}$ ). Essa medição aconteceu somente no início dos experimentos, pois os aparelhos de arcondicionado foram preparados para trabalhar sempre com a mesma velocidade.

\section{Estimativa de temperaturas internas horárias}

Neste trabalho, optou-se pela análise comparativa, relacionando as temperaturas internas do ar da configuração experimental (TR) com o desempenho da configuração original. A opção pelo método preditivo eliminou a necessidade de mais edificações-teste, possibilitando monitoramentos em sequência em 
vez de monitoramentos paralelos. Os procedimentos relativos ao método preditivo são apresentados em detalhes em Krüger et al. (2017). O método estima a variação horária das temperaturas internas $\left(\Delta T_{\text {in }}\right)$ como função da diferença entre a temperatura interna em dado momento $\left(T_{i n}^{t-1}\right)$ e a temperatura externa na hora seguinte $\left(T_{e x}^{t}\right)$. Somando-se essa estimativa de variação da temperatura, no intervalo de 1 hora (de $t$ - 1 para $t$ ), com a temperatura interna da hora anterior à variação $(t-1)$, tem-se a estimativa da temperatura interna horária para o momento $t$ (Equação 1).

$T_{a \text { in }}^{t}=T_{a \text { in }}^{t-1}+\alpha\left(T_{a \text { ex }}^{t}-T_{a \text { in }}^{t-1}\right)$

Eq. 1

Em que:

$T_{\text {a in }}^{t}$ é a temperatura interna $\left({ }^{\circ} \mathrm{C}\right)$ estimada no instante $t$;

$T_{\text {a in }}^{t-1}$ a temperatura interna $\left({ }^{\circ} \mathrm{C}\right)$ estimada ou medida no instante $t-1$;

$T_{a \text { ex }}^{t}$ a temperatura externa $\left({ }^{\circ} \mathrm{C}\right)$ medida no instante $t$;

$\alpha$ é uma função que descreve a variação proporcional da temperatura interna em função da diferença entre $T_{a \text { ex }}^{t-n}$ e $T_{a \text { in }}^{t-1}$.

Os valores médios de $\alpha$ determinam como a edificação se relaciona com a temperatura externa (Equação 2):

$\alpha=\frac{T_{a \text { in }}^{t}-T_{a \text { in }}^{t-1}}{T_{a \text { ex }}^{t}-T_{a \text { in }}^{t-1}}$

Quanto mais a diferença entre a temperatura externa $\left(T_{a \text { ex }}^{t}\right)$ e a temperatura interna $\left(T_{a \text { in }}^{t-1}\right)$ se afastar de zero, mais os valores de $\alpha$ tenderão a estabilizarem em torno de dois valores médios:

(a) um valor médio para quando predominarem as perdas térmicas, do ambiente interno para o ambiente externo, denominado " $\alpha$ médio para perdas", e

(b) outro valor médio, para quando predominarem os ganhos térmicos, denominado " $\alpha$ médio para ganhos". O uso do modelo preditivo contempla três etapas:
(a) calibração;
(b) validação; e
(c) aplicação.

\section{Questionário e procedimentos para aplicação e recrutamento de voluntários}

Os voluntários foram recrutados entre os membros da comunidade universitária local (estudantes, funcionários e seus familiares) da Midreshet. O questionário foi aplicado impresso e respondido individualmente. Cada voluntário participou de apenas uma sessão de testes. O tempo de permanência no experimento era de \pm 35 minutos. Os horários de chegada foram agendados previamente, segundo a disponibilidade dos participantes, podendo ocorrer de manhã (das $8 \mathrm{~h}$ às 11h30) ou à tarde (das 13h às 19h), em dias úteis. Ao chegarem à edificação-teste, solicitava-se aos voluntários que tomassem lugar em uma estação de trabalho e experienciassem o ambiente térmico, enquanto os procedimentos eram explicados. Após a explicação, eram deixados sozinhos na sala, instruídos a permanecerem sentados e a não alterarem demasiadamente a posição de suas cadeiras. Ficavam livres para ler, estudar ou usar o celular. As respostas referentes à percepção térmica aqui apresentadas eram informadas pelos voluntários entre 30 e 35 minutos após a chegada ao experimento.

O questionário foi apresentado em inglês e elaborado de acordo com as diretrizes da ISO 10551 (INTERNATIONAL..., 1995). Os voluntários foram solicitados a responder questões sobre:

(a) dados pessoais (biometria, tempo de residência em Israel, país de origem, ambiente térmico anterior ao teste e modo de transporte até a edificação-teste);

(b) informações sobre vestuário (listas de roupas para composição do traje), preenchidas pelo aplicador; e

(c) questões sobre percepção térmica.

Em relação à percepção térmica, os voluntários eram solicitados a indicar suas respostas em escalas avaliativas do tipo Likert, de 7 pontos (Figura 7) (INTERNATIONAL..., 1995). Foram utilizadas três métricas: sensação térmica (ST), conforto térmico (CT) e preferência térmica (PT). 
A partir dos valores declarados para a ST, foi calculado o número de pessoas insatisfeitas. Consideraram-se pessoas termicamente insatisfeitas aquelas que votaram muito quente, quente, frio ou muito frio, na escala de sensibilidade térmica (INTERNATIONAL..., 2005). Também foram calculados os valores médios para as ST. Posteriormente, foram confrontados os dados estimados (PMV e PPD) e reportados.

Para maior confiabilidade da pesquisa, foi realizada uma aplicação-piloto do questionário entre os dias 26 e 27 de julho, com a participação de seis voluntários. Essa aplicação-piloto resultou em pequenos justes nos termos em inglês adotados nas questões.

\section{Descrição da amostra}

A aplicação dos questionários de conforto começou no dia 31 de julho e terminou no dia 21 de agosto de 2017. Foram 46 participantes, dos quais 19 homens (média de idade 33,9 anos) e 27 mulheres (média de idade 31,7 anos). A média de idade geral foi de 32,6 anos e o desvio padrão de 8,8 anos. 91,3\% dos respondentes possuíam idade de 16 até 40 anos, fazendo com que a maioria da amostra fosse composta por jovens adultos. O índice de massa corporal (IMC, calculado como o peso corporal dividido pelo quadrado da altura corporal, expresso em $\mathrm{kg} / \mathrm{m}^{2}$ ) variou entre 18,4 e $35,5 \mathrm{~kg} / \mathrm{m}^{2}$, "abaixo do peso" até "obesidade grau II", de acordo com as categorias da Organização Mundial da Saúde (WORLD..., 1995). O IMC médio foi $23,4 \mathrm{~kg} / \mathrm{m}^{2}$ e o desvio padrão foi de $3,61 \mathrm{~kg} / \mathrm{m}^{2}$. O peso médio foi $67,1 \mathrm{~kg}$ e seu desvio padrão foi $12,91 \mathrm{~kg}$. A altura média foi $1,69 \mathrm{~m}$ e o desvio padrão foi de $0,08 \mathrm{~m}$. Os participantes eram originários de 13 países diferentes:

(a) Israel (25 participantes, 54,3\%);

(b) EUA (5), Índia (3);

(c) Brasil (2);

(d) Alemanha (2);

(e) Rússia (2); e

(f) outros países (7)

Sobre o ambiente em que estiveram anteriormente, a maioria havia acabado de vir de ambientes térmicos sem ar-condicionado (63,04\%), alguns de espaços com ar-condicionado (30,43\%) e alguns de transportes públicos/carros, com ar-condicionado (6,52\%). 32 dos voluntários chegaram ao local do experimento caminhando (69,57\%), 10 chegaram de bicicleta $(21,74 \%)$ e 4 de carro/ônibus $(8,7 \%)$. O deslocamento ao local do experimento, segundo reportado, durou menos do que 10 minutos para $45(97,83 \%)$ participantes. O nível de isolamento térmico das vestimentas (clo) variou de 0,23 a 0,74 clo. A média foi 0,32 clo e a mediana foi 0,24 clo. 30 pessoas $(65,22 \%)$ utilizaram vestimenta com isolamento entre 0,23 e 0,29 clo. $\mathrm{O}$ traje mais comum dos voluntários foi: camiseta de manga curta, bermuda, roupas de baixo e sandálias.

Figura 7 - Questões sobre sensação térmica (ST), conforto térmico (CT) e preferência térmica (PT)

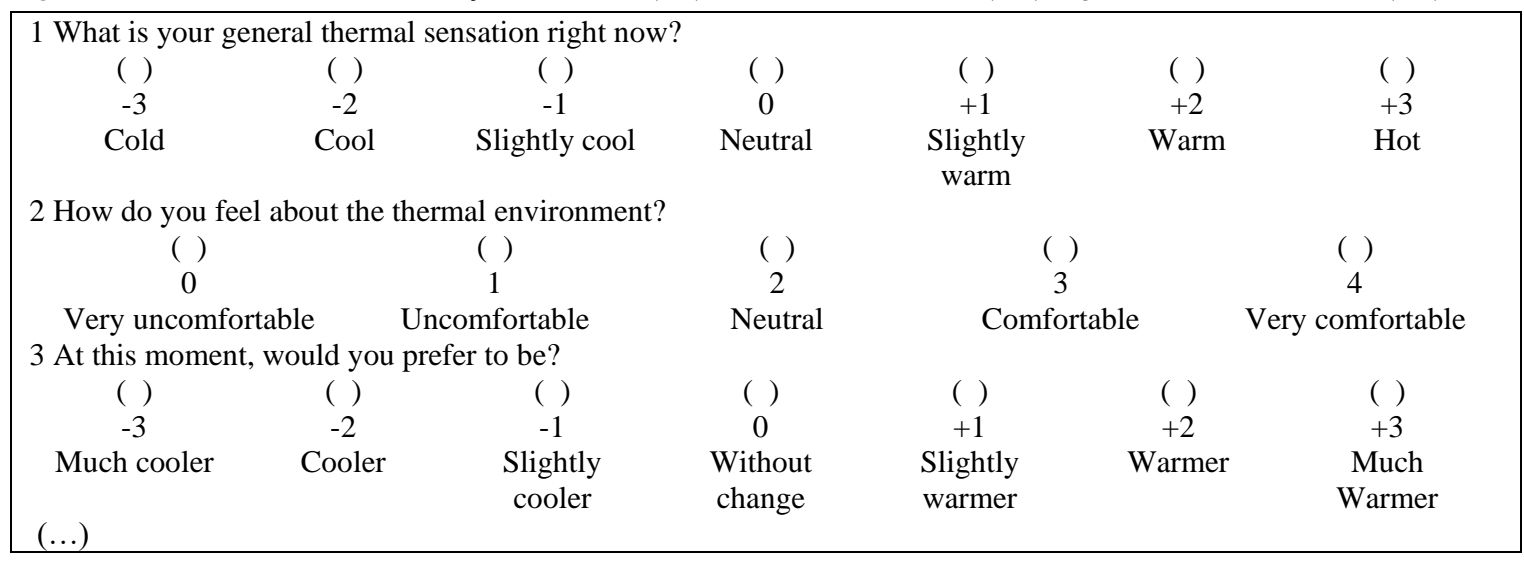

342 Fernandes, L. C.; Krüger, E. L.; Motzafi-Haller, W. 


\section{Condições térmicas no ambiente experimental}

As condições térmicas na sala TR eram conferidas 30 minutos antes da chegada dos voluntários e novamente 35 minutos após. O índice escolhido para representar tais condições térmicas foi o voto médio predito (PMV). O PMV foi calculado conforme a ISO 7730 (INTERNATIONAL..., 2005), considerando-se as variáveis $T_{a}, U R$ e $T_{r m}$ (temperatura radiante média) com $v_{a}$ mantida fixa. Para o cálculo do PMV, foi adotada uma pessoa padrão do sexo masculino, com 35 anos, 1,75 m de altura, $75 \mathrm{~kg}$ (DANESHVAR; BAGHERZADEH; TAVOUSI, 2013), vestindo roupa leve (0,3 clo) e em atividade sedentária $(70 \mathrm{~W})$. Utilizaram-se o programa computacional WinComf, descrito por Fountain e Huizenga (1996), e a ferramenta de cálculo online do CBE (Hoyt et al., 2017). Os dados apresentados neste estudo foram registrados pelos voluntários entre 30 e 35 minutos após sua chegada ao experimento.

Considerando a ISO 7726 (INTERNATIONAL..., 1998), a $T_{r m}$ foi calculada considerando as temperaturas superficiais $\left(T_{S}\right)$ e o fator de forma $(F)$. O cálculo a partir do $F$ leva em conta um ponto de interesse na sala (posição dos sensores) e dá mais importância para a temperatura das superfícies que apresentarem os maiores ângulos sólidos em relação ao ponto escolhido (ROMANA et al., 2013). O ângulo sólido $(\Omega)$ é um conceito geométrico que dá uma ideia quantitativa da abertura com a qual uma superfície (ou objeto) determinada é vista a partir de um ponto. Corresponde à área da projeção da superfície ou objeto sobre uma esfera cujo centro é o ponto de interesse e mede o tamanho aparente do objeto visto a partir desse ponto (SOLDOVIERI; VILORIA, 2016). Dado um ponto de interesse em uma sala de planta retangular, a soma dos ângulos sólidos das superfícies que a delimitam será igual à área de uma esfera dada em esferorradianos ( $4 \pi$ ou 12,566). Tomando-se o ponto de interesse como o vértice e uma superfície (parede, por exemplo) como a base de uma pirâmide, pode-se estimar o ângulo sólido dado por essa superfície com a Equação 3 (FERNÁNDEZ-GONZÁLEZ; COSTACHE, 2012):

$\Omega=4 \tan ^{-1}\left(\frac{a b}{2 d\left(4 d^{2}+a^{2}+b^{2}\right)^{0,5}}\right)$

Eq. 3

Em que:

$\Omega_{\mathrm{i}}$ é o ângulo sólido dado pela superfície em relação ao ponto de interesse;

a o comprimento da base da pirâmide (comprimento da parede);

b a largura da base da pirâmide (altura da parede); e

$\mathrm{d}$ a distância entre o centro da base e o topo da pirâmide.

O fator de forma (F) (Equação 4) corresponde ao ângulo sólido relativo em torno de um ponto.

$F_{i}=\frac{\Omega_{i}}{4 \pi}$

De acordo com a ISO 7726 (INTERNATIONAL..., 1998), a $T_{r m}$ pode ser estimada por esse método tendo em conta as temperaturas das superfícies internas e seus respectivos $F$ utilizando a Equação 5:

$T_{\text {rm Fator de forma }}=\sum\left(F_{i} T_{s}\right)$

Na qual $T_{s}$ é a temperatura de uma superfície e $F_{i}$ seu fator de forma a partir de um ponto de interesse.

Ainda visando avaliar as condições ambientais internas, para as configurações original e experimental, também foram analisadas:

(a) a flutuação térmica diária, dada pelo fator decremental (f); e

(b) a resistência ao aquecimento, dada pelo coeficiente de dissemelhança (CD).

O fator decremental (f) é expresso pela Equação 6:

$f=\frac{\left(T_{a} \text { máx }-T_{a} \text { mín }\right)_{i n}}{\left(T_{a} \text { máx }-T_{a \text { mín }}\right)_{e x}}$

Onde $\left(\mathrm{T}_{\mathrm{a} \text { máx }}-\mathrm{T}_{\mathrm{a} \text { mín }}\right)_{\text {in }}$ e $\left(\mathrm{T}_{\mathrm{a} \text { máx }}-\mathrm{T}_{\mathrm{a} \text { mín }}\right)_{\text {ex }}$ são as amplitudes térmicas diárias interna e externa, respectivamente.

O coeficiente de dissemelhança (CD) (Equação 7) indica se, ao longo de um ciclo de 24 horas, o artifício passivo para condicionamento resultou em um saldo de aquecimento (valores positivos) ou resfriamento (valores negativos) (KRÜGER et al., 2018). 
$C D=\left(\frac{T_{a \text { in méd }}-T_{a} \text { ex mín }}{T_{\text {a ex méd }}-T_{\text {a ex mín }}}\right)-1$

Eq. 7

Em que:

$\mathrm{T}_{\mathrm{a}}$ in méd é a temperatura interna média;

$\mathrm{T}_{\mathrm{a}}$ ex mín é a temperatura externa média; e

$\mathrm{T}_{\mathrm{a}}$ ex méd é a temperatura externa média.

\section{Parâmetros para avaliação da percepção térmica reportada pelos voluntários}

Como parâmetros para análise das percepções térmicas reportadas pelos voluntários, tomaram-se os seguintes modelos:

(a) o PMV, calculado conforme a ISO 7730 (INTERNATIONAL..., 2005) e descrito anteriormente;

(b) a faixa de conforto para edificações passivas definida pela Standard 55 (AMERICAN..., 2017); e

(c) a faixa de conforto para edificações passivas definida pela norma EN 15251 (EUROPEAN..., 2007).

A partir dos valores calculados para o PMV também foram calculados os valores para o percentual de pessoas insatisfeitas (PPD). O PPD (Equação 8) permite estimar o percentual de pessoas que se sentirão desconfortáveis, por calor ou frio. As pessoas termicamente insatisfeitas são aquelas que votarão muito quente, quente, frio ou muito frio na escala de sensibilidade térmica de sete pontos sugerida pela ISO 7730. Com o valor PMV determinado, pode-se calcular o valor do PPD usando a Equação 8 a seguir (INTERNATIONAL..., 2005):

$P P D=100-95 * \exp \left(-0,03353 * P M V^{4}-0,2179 * P M V^{2}\right)$

Eq. 8

Os modelos para edificações passivas dados pelas normas Standard 55 (AMERICAN..., 2013) e EN 15251 (EUROPEAN..., 2007) preveem o uso da temperatura operativa $\left(T_{o}\right)$ para cálculo das temperaturas neutras e das faixas de conforto. O cálculo dessa variável demanda a determinação da $T_{r m}$. Quando a $v_{a}$ no ambiente for menor que $0,2 \mathrm{~m} / \mathrm{s}$, a $T_{o}$ pode ser tomada como a média entre a $T_{r m}$ e a $T_{a}$ (INTERNATIONAL..., 2010; INSTITUTO..., 2010). Adotou-se esse procedimento, pois a velocidade máxima do ar nas sessões foi fixada em $0,2 \mathrm{~m} / \mathrm{s}$ e quando os aparelhos estavam desligados se supôs que esse valor fosse de $0,0 \mathrm{~m} / \mathrm{s}$.

O modelo para edificações sem sistemas de resfriamento mecânico da norma EN 15251 (EUROPEAN..., 2007) adota uma faixa de conforto variável conforme as médias das temperaturas externas diárias. A faixa é definida em torno de uma temperatura operativa neutra $\left(T_{o \text { conf }}\right)$ (Equação 9$)$.

$T_{\text {o conf }}=0,33 T_{\text {ex méd ep }}+18,8$

Eq. 9

Em que $T_{o \text { conf }}$ é a temperatura operativa neutra (ou de conforto) e $T_{\text {ex méd ep }}$ é a temperatura externa média exponencialmente ponderada.

A $T_{\text {ex méd ep }}$ pode ser calculada por meio da Equação 10:

$T_{\text {ex méd ep }}=(1-\beta) \times T_{\text {ex méd }-1}+\beta \times T_{\text {ex méd ep }-1}$

Eq. 10

Na qual:

$\beta$ constante, recomenda-se utilizar 0,8 (EUROPEAN..., 2007);

$T_{\text {ex méd }-1}$ temperatura externa média do dia anterior $\left({ }^{\circ} \mathrm{C}\right)$; e

$T_{\text {ex méd ep }-1}$ temperatura externa média exponencialmente ponderada, calculada para o dia anterior.

Neste trabalho foi adotada a faixa para "novas construções e reformas com expectativa normal", com largura de $6{ }^{\circ} \mathrm{C}$ (NICOL; WILSON, 2010). Quando a temperatura externa média exponencialmente ponderada $\left(T_{\text {ex méd ep }}\right.$ ) apresentar valores inferiores a $10^{\circ} \mathrm{C}$, o limite superior será $26{ }^{\circ} \mathrm{C}$ e o limite inferior será $20^{\circ} \mathrm{C}$ (EUROPEAN..., 2007).

O modelo para edificações naturalmente condicionadas da norma americana Standard 55 (AMERICAN..., 2017) também adota faixas de conforto variáveis e definidas a partir das médias das temperaturas externas. O procedimento é aplicável apenas para quando as temperaturas médias mensais forem superiores ou iguais a $10{ }^{\circ} \mathrm{C}$ e inferiores ou iguais a $33,5{ }^{\circ} \mathrm{C}$ (AMERICAN..., 2017). Alerta-se para o fato de que houve

344 Fernandes, L. C.; Krüger, E. L.; Motzafi-Haller, W. 
alterações nos procedimentos, da versão de 2010 (AMERICAN..., 2010) para a versão de 2013 (AMERICAN..., 2013). Na última, a $T_{o \text { conf }}$ é calculada pela Equação 11.

$T_{\text {o conf }}=0,31 T_{\text {ex méd } m}+17,8$

Na qual $T_{\text {ex méd } m}$ é a média móvel das temperaturas externas $\left({ }^{\circ} \mathrm{C}\right)$.

Observa-se que a $T_{\text {ex méd } m}$ é uma média aritmética móvel, diferindo da variável utilizada pela EN 15251 (EUROPEAN..., 2007), que utiliza média ponderada. Deve basear-se em não menos que 7 e não mais que 30 dias consecutivos antes do dia em questão (AMERICAN..., 2013). Adotou-se, em torno da temperatura neutra, a faixa de aceitabilidade térmica com $7{ }^{\circ} \mathrm{C}$ de largura, para atendimento de $80 \%$ da população (AMERICAN..., 2017).

\section{Resultados}

\section{Condições ambientais externas e internas no período de 31/07 até 21/08}

\section{Desempenho térmico da sala de testes}

Comparativamente à configuração original da cobertura, a instalação do TR acoplado aos painéis radiantes, no período de aplicação dos questionários, resultou na redução de $1,8{ }^{\circ} \mathrm{C}$ na temperatura média da edificação. A adoção do TR também resultou na alteração do $\mathrm{CD}$, que passou de 0,41 , na configuração original, para 0,03 , na configuração TR, eliminando o saldo de aquecimento (valor médio para o período de $31 / 07$ a 21/08).

Como exemplo, para o dia 19/08/2017, a Figura 8 apresenta comparação entre as temperaturas do ar internas e externas medidas quando com a configuração TR e as temperaturas internas estimadas considerando a configuração original. Para o mesmo dia, a Figura 9 apresenta as temperaturas do ar internas e externas e as temperaturas superficiais internas. Foram observadas diferenças de aproximadamente $3{ }^{\circ} \mathrm{C}$ entre as temperaturas superficiais dos painéis radiantes (com valores menores) e do piso e paredes. Se considerados os limites indicados por Fanger et al. (1985) e pela Standard 55 (AMERICAN..., 2017), as assimetrias estavam dentro das faixas de tolerância. Fanger et al. (1985) mostraram que, no geral, as pessoas são mais tolerantes a tetos e paredes frios que a tetos e paredes quentes.

Os resultados são diferentes daqueles observados em edificações convencionais, nas quais as temperaturas superficiais do teto tendem a flutuar de modo mais expressivo e, durante o dia, apresentar valores mais altos que as do ar (LAMBERTS, 1988). Szokolay (2008) argumenta que, em climas quentes, em que predomina o uso de roupas leves, a temperatura radiante média é duas vezes mais influente para a sensação térmica que a temperatura do ar. Ou seja, os voluntários desse experimento foram expostos a condições distintas das usuais, as quais foram definidas sobretudo pelas trocas térmicas através da cobertura.

Os ambientes térmicos externo e interno, no período da aplicação dos questionários (31/07 - 21/08), apresentaram condições distintas. A Tabela 1 apresenta os valores máximos, mínimos e médios para a temperatura do ar, amplitude térmica diária, fator decremental e PMV. A Figura 10 permite visualizar a relação entre temperaturas externas e internas do ar. Fica clara a relativa estabilidade das temperaturas internas do ar (FD máximo 0,13) comparativamente às flutuações observadas no ambiente externo.

Embora $80 \%$ das sessões com voluntários ocorreram entre as $9 \mathrm{~h}$ e as $17 \mathrm{~h}$, período do dia no qual as temperaturas externas do ar eram predominantemente mais altas que as internas (Tabela 1 e Figura 10), não se pode dizer que essa diferença tenha repercutido sobre as respostas dos participantes, pois os votos aqui considerados foram registradas após o período de aclimatação de curto prazo, que é atingido aos 20/30 minutos em um ambiente (AULICIEMS; SZOKOLAY, 2007).

Por outro lado, a configuração TR propiciou temperaturas internas do ar mais baixas que as observadas na configuração original, sem apresentar assimetrias térmicas entre as temperaturas superficiais que pudessem comprometer o desempenho térmico do ambiente interno. Comparativamente ao ambiente externo, o ambiente interno apresentou grande estabilidade térmica e temperaturas internas médias mais baixas. 
Figura 8 - Temperaturas externas e internas* do ar nas configurações experimental e original

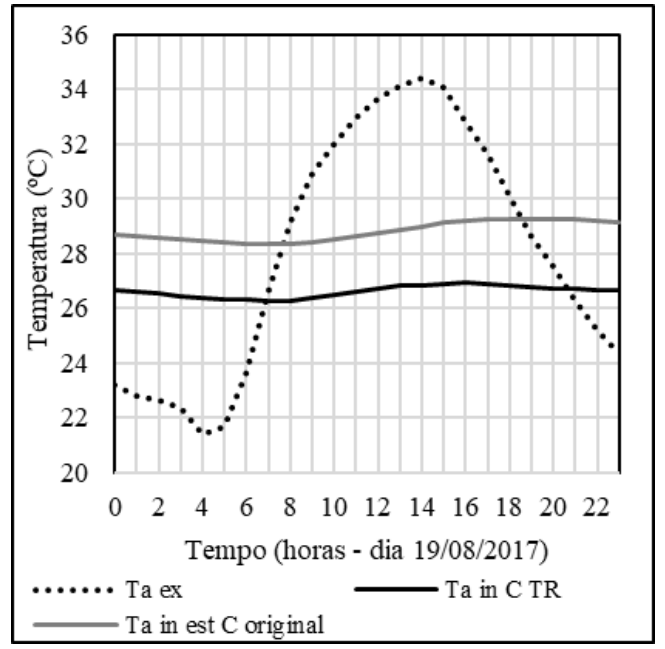

Nota: *medidas na configuração experimental e estimadas para a configuração original.

Figura 9 - Temperaturas internas do ar e temperaturas superficiais na configuração experimental

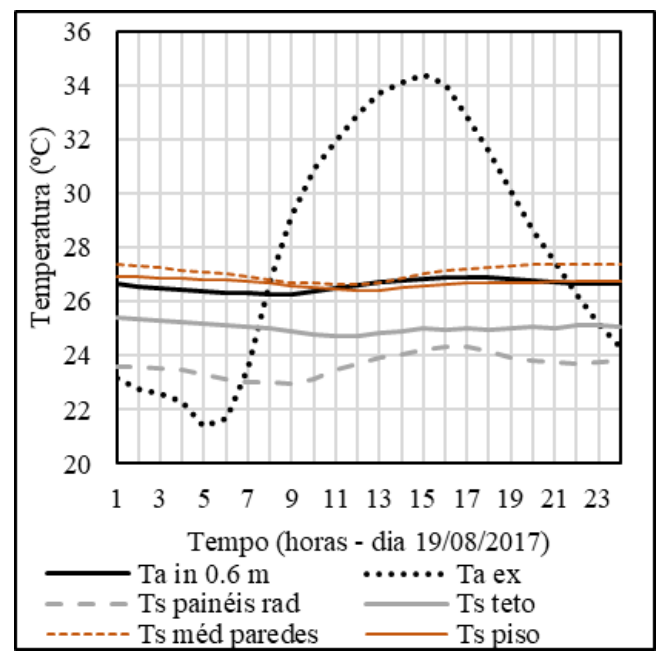

Nota: *medidas na configuração experimental e estimadas para a configuração original.

Tabela 1 - Valores máximos, mínimos e médios das temperaturas do ar, amplitudes térmicas diárias, fator decremental e PMV

\begin{tabular}{l|c|c|c|c|c|c}
\hline & Ta ex $\left({ }^{\circ} \mathbf{C}\right)$ & Ta in $\left({ }^{\circ} \mathbf{C}\right)$ & $\begin{array}{c}\text { Amplitude } \\
\text { externa }\left({ }^{\circ} \mathbf{C}\right)\end{array}$ & $\begin{array}{c}\text { Amplitude } \\
\text { interna }\left({ }^{\circ} \mathbf{C}\right)\end{array}$ & FD & PMV interno \\
\hline Máximo & 34,98 & 28,30 & 14,57 & 1,46 & 0,13 & 0,20 \\
Médio & 26,96 & 27,07 & 12,43 & 0,84 & 0,07 & $-0,08$ \\
Mínimo & 19,54 & 25,93 & 10,23 & 0,44 & 0,03 & $-0,57$ \\
\hline
\end{tabular}


Figura 10 - Temperaturas externas e internas do ar para o período de 31/07 até 21/08

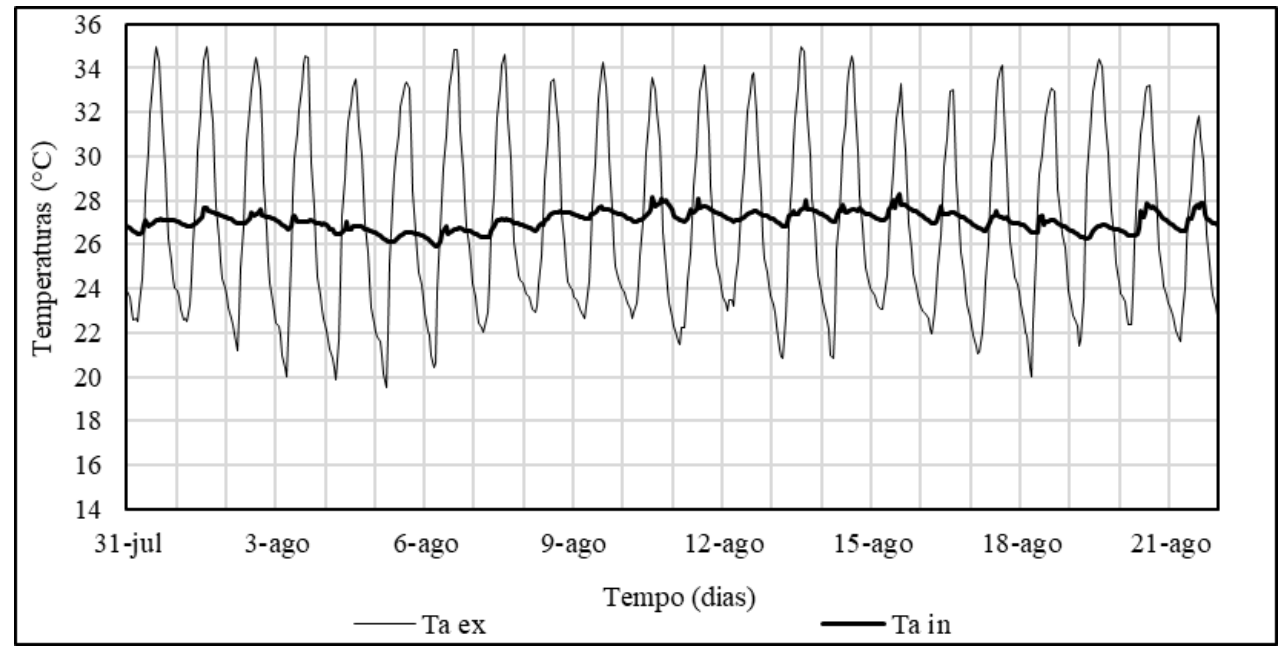

\section{Condições ambientais nos momentos das sessões de aplicação dos questionários}

No ambiente externo, durante as sessões de aplicação dos questionários, a $T_{a}$ ex máxima foi $34,6{ }^{\circ} \mathrm{C}$, a média foi $29,6{ }^{\circ} \mathrm{C}$ e a mínima foi $24,3{ }^{\circ} \mathrm{C}$ (Figura 11 ).

No ambiente interno, durante as sessões, a $v_{a}$, controlada por aparelho, foi mantida constante $(0,2 \mathrm{~m} / \mathrm{s})$. As variáveis $T_{a \text { in }}, T_{r m}$ in e $U R$ apresentaram valores próximos na quase totalidade das sessões. A $T_{a}$ in máxima foi $28,8^{\circ} \mathrm{C}$, a média foi $27,23{ }^{\circ} \mathrm{C}$ e a mínima foi $25,8{ }^{\circ} \mathrm{C}$ (amplitude de apenas $2{ }^{\circ} \mathrm{C}$ ). Ou seja, os voluntários foram expostos a condições ambientais internas sem grandes discrepâncias.

Por outro lado, durante algumas sessões, ocorreram diferenças expressivas entre as temperaturas externas e internas do ar. A diferença máxima entre a $T_{a \text { ex }}$ e a $T_{a \text { in }}$, nos momentos das sessões, foi de $6,8{ }^{\circ} \mathrm{C}$. Na maioria das sessões, as temperaturas externas do ar eram mais altas que as internas (Figura 11).

\section{Voto médio predito (PMV) e percentual de pessoas insatisfeitas (PPD)}

Para uma análise inicial, eram calculados os valores para o voto médio predito (PMV) e percentual de pessoas insatisfeitas (PPD) (Figura 12). Em geral, os valores para o PMV ficaram próximos da condição de neutralidade térmica (valor médio de $-0,08$ e oscilação entre $-0,57$ e 0,20 ). Os valores para o PPD ficaram próximos ou abaixo de $10 \%$ (média de $6,2 \%$ e oscilação entre $4,9 \%$ e 13,2\%). Ou seja, segundo o modelo PMV, os voluntários foram sujeitos a condições ambientais confortáveis ou próximas da faixa de conforto nos momentos das sessões.

\section{Temperaturas operativas nos momentos das sessões frente aos modelos adaptativos}

As temperaturas operativas dos momentos das sessões foram plotadas sobre as faixas de conforto dadas pelas normas Standard 55 (AMERICAN..., 2017) (Figura 13) e EN 15251 (EUROPEAN..., 2007) (Figura 14). Os valores médios para as duas faixas de conforto são apresentados na Tabela 2 . No caso da faixa de conforto da ASHRAE, as temperaturas operativas situaram-se entre o limite superior da faixa de conforto e a linha de neutralidade. No caso da faixa de conforto da EN 15251, as temperaturas operativas ficaram, no geral, mais próximas das temperaturas neutras. Ou seja, nos momentos das sessões, as temperaturas operativas eram mais próximas do adequado para o modelo da EN 15251 do que para o modelo da ASHRAE.

Se, por um lado, a aclimatação de curto prazo não deve ter impactado os votos dos voluntários (AULICIEMS; SZOKOLAY, 2007), por outro cabe salientar que os modelos adaptativos são fundamentados na aclimatação de longo prazo (DE DEAR; BRAGER; COOPER, 1997). A verificação de condições ambientais internas próximas das ideais, segundo os dois modelos adaptativos considerados, indicou, de antemão, que havia grande probabilidade de que os votos dos voluntários iriam indicar satisfação com o ambiente térmico propiciado pelo sistema de resfriamento. 
Figura 11 - Temperaturas internas e externas do ar durante as sessões de aplicação dos questionários e UR internas

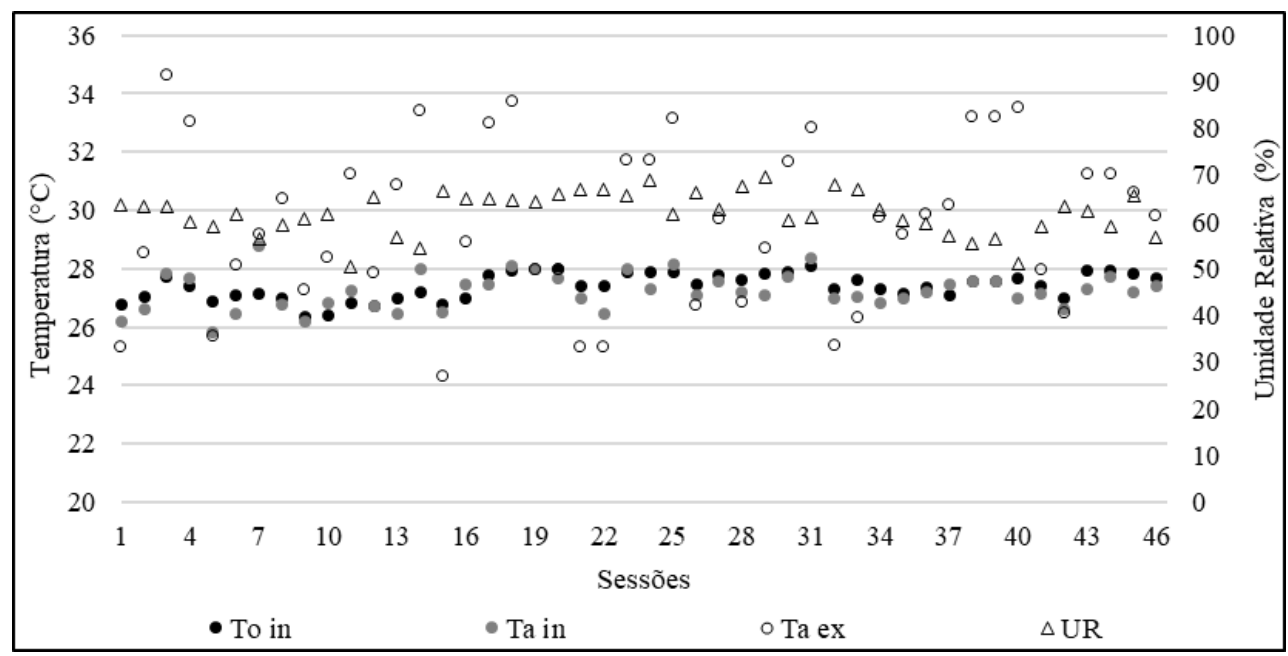

Figura 12 - PMV e PPD durante as sessões de aplicação dos questionários



Figura 13 - Temperaturas operativas na sala TR e faixa de conforto segundo a ASHRAE



348 Fernandes, L. C.; Krüger, E. L.; Motzafi-Haller, W. 
Figura 14 - Temperatura operativa na sala TR e faixa de conforto segundo a EN 15251

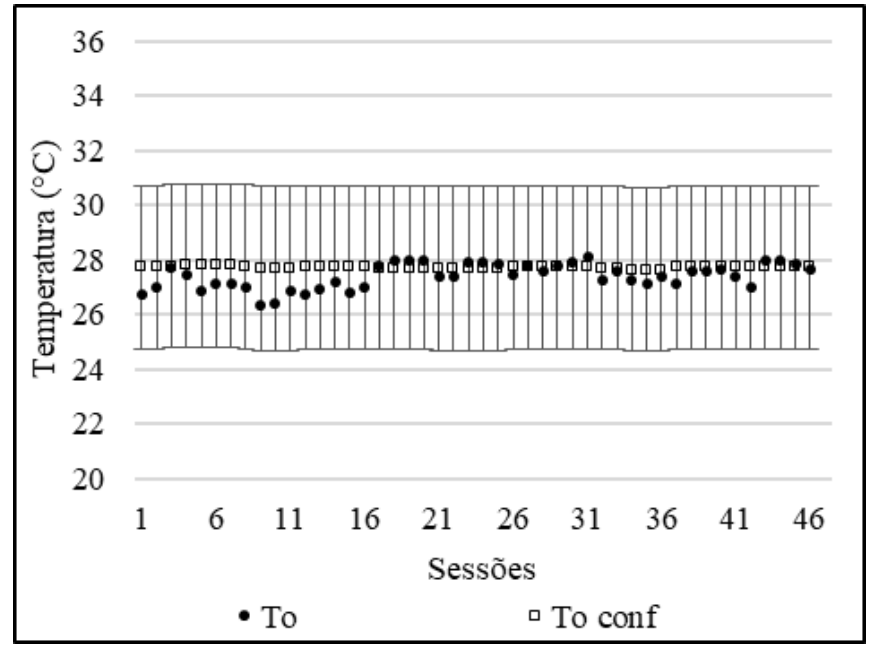

Tabela 2 - Médias das faixas de conforto para as normas Standard 55 e EN 15251

\begin{tabular}{l|c|c}
\hline & $\begin{array}{c}\text { Standard 55 } \\
\text { (AMERICAN..., 2017) }\end{array}$ & $\begin{array}{c}\text { EN 15251 } \\
\text { (EUROPEAN..., 2007) }\end{array}$ \\
\hline Média do limite superior $\left({ }^{\circ} \mathrm{C}\right)$ & 29,7 & 30,7 \\
Média da linha de neutralidade térmica $\left({ }^{\circ} \mathrm{C}\right)$ & 26,2 & 27,7 \\
Média do limite inferior $\left({ }^{\circ} \mathrm{C}\right)$ & 22,7 & 24,7 \\
\hline
\end{tabular}

\section{Respostas dos voluntários quanto aos ambientes térmicos Sensação térmica (ST) reportada}

Em relação à ST, os votos foram favoráveis ao sistema, indicando que ele foi efetivo em propiciar condições térmicas próximas daquelas consideradas neutras pelos voluntários. 50\% dos voluntários (Figura 15) reportaram neutralidade em relação ao ambiente térmico da sala de testes e 30,4\% reportaram leve sensação de frio. A média dos valores dos votos declarados para a ST também apresentou boa concordância com a média estimada como adequada segundo o modelo PMV. A média dos valores das temperaturas operativas (Tabela 3) quando do voto neutro foi $27,3{ }^{\circ} \mathrm{C} .1,1{ }^{\circ} \mathrm{C}$ acima do indicado como neutro pela norma Standard 55 (Tabela 2) e $0,4^{\circ} \mathrm{C}$ abaixo do valor indicado pela norma EN 15251. Ou seja, quanto à ST, ocorreu maior concordância com a EN 15251.

O ambiente foi considerado satisfatório para 93,5\% dos voluntários (Tabela 3), indicando alto grau de concordância como o modelo de Fanger, adotado pela ISO 7730 (INTERNATIONAL..., 2005), a partir do qual foi estimado que 93,8\% dos participantes declarariam satisfação com o ambiente térmico. Observa-se que, embora existam diferenças entre os experimentos, essa taxa de satisfação é superior à taxa verificada por Bravo e González (2013) em estudo sobre percepção térmica em uma edificação na cidade de Maracaibo, Venezuela, dotada de teto-reservatório metálico. Naquele experimento, obteve-se $60 \%$ de satisfeitos para o ambiente testado.

\section{Conforto térmico (CT)}

Quando os voluntários foram solicitados a classificar o ambiente em relação ao conforto térmico (CT), a média dos valores dos votos declarados foi 2,72 (entre neutro e confortável). A condição mais votada foi confortável (43,5\%), o valor mínimo foi 1 (desconfortável) e o valor máximo foi 4 (muito confortável) (Figura 16). Os valores médios das temperaturas operativas quando dos votos neutro, confortável e muito confortável foram: $27,5^{\circ} \mathrm{C}, 27,4{ }^{\circ} \mathrm{C}$ e $27,1^{\circ} \mathrm{C}$ (Figura 17). 


\section{Preferência térmica (PT)}

Em se tratando das preferências térmicas (Figura 18), 30,4\% dos participantes votaram por "um pouco mais frio" e $65,2 \%$ por "sem mudanças". A média das temperaturas operativas das sessões daqueles que optaram pela primeira opção foi $27,4^{\circ} \mathrm{C}$ e a das sessões dos que optaram pela segunda foi $27,3{ }^{\circ} \mathrm{C}$.

\section{Discussão dos resultados}

Em resumo, considerando as respostas dos voluntários quanto ao ambiente térmico: a maior parte reportou sensação de "neutralidade térmica" quanto à ST; a condição mais votada quanto ao CT foi "confortável"; e, quanto à PT, a maioria dos participantes votou na opção "sem mudanças". Ou seja, o ambiente condicionado por painéis radiantes acoplados ao TR foi capaz de prover condições adequadas aos voluntários.

Na maior parte das sessões, o ambiente externo apresentou condições diferentes das internas (Figura 10); no entanto, não se pode dizer que ocorreu impacto sobre as respostas dos voluntários, pois estas foram registradas após 30 minutos no experimento, findado o período de aclimatação de curto prazo (AULICIEMS; SZOKOLAY, 2007). Esse apontamento está em concordância com o experimento de Imanari, Omori e Bogaki (1999), que compararam o desempenho de um sistema de resfriamento/aquecimento por meio de um elemento radiante suspenso e junto ao teto de um escritório com o de um sistema convencional de ar condicionado. Naquele experimento, embora as condições térmicas nos dois casos fossem semelhantes, o resfriamento radiante obteve maior percentual de votos em conforto que o sistema baseado em trocas convectivas. Percebeu-se que a diferença quanto aos níveis de conforto aumentava conforme o tempo de permanência do indivíduo no ambiente. Ou seja, que a aclimatação de curto prazo perde importância conforme aumenta o tempo de permanência no ambiente, o que também foi observado por Krüger $e t$ al. (2015).

O sistema de resfriamento analisado, embora se baseie no efeito radiante dos painéis localizados junto ao teto, também se beneficia do resfriamento estrutural do teto-reservatório, uma vez que o reservatório de água foi aplicado diretamente sobre a laje. A redução do fluxo térmico é o principal efeito esperado em ambientes providos de TR (RUNSHENG; ETZION; ERELL, 2003) e, no caso da edificação-teste analisada, devido a sua grande massa térmica (ERELL et al., 1992), há uma contribuição adicional para a estabilização térmica interna, demonstrada pela baixa amplitude térmica medida, em média cerca de $6 \%$ apenas da flutuação térmica externa (Cf. Tabela 1).

A média dos valores dos votos quanto à ST $(-0,22)$ ficou próxima da média dos valores calculados para o PMV (-0,08), indicando concordância com esse modelo. O número de pessoas insatisfeitas (Tabela 3) também apresentou valor próximo ao estimado (PPD). A concordância entre dados subjetivos e preditos pelo modelo PMV também foi observada em estudos prévios realizados com resfriamento radiante a partir da laje de teto por Loveday et al. (1998) e Tian e Love (2008).

Figura 15 - Votos quanto à sensação térmica (ST)

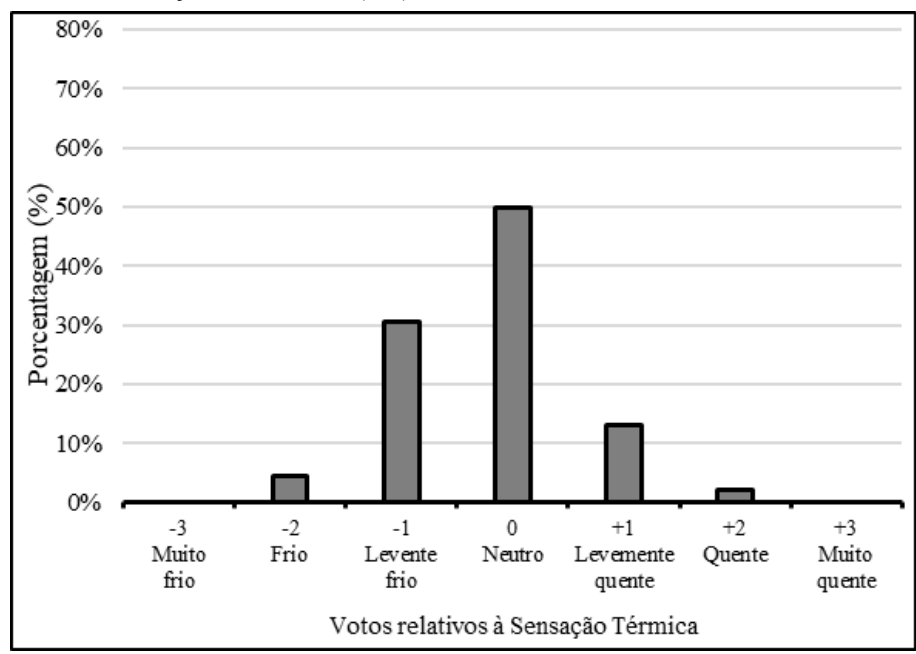

350 Fernandes, L. C.; Krüger, E. L.; Motzafi-Haller, W. 
Tabela 3 - PMV e PPD versus dados reportados

\begin{tabular}{c|c|c|c|c|c|c}
\hline & $\begin{array}{c}\text { PMV } \\
\text { médio }\end{array}$ & $\begin{array}{c}\text { ST média } \\
\text { reportada }\end{array}$ & Diferença & $\begin{array}{c}\text { PPD } \\
(\boldsymbol{\%})\end{array}$ & $\begin{array}{c}\text { Porcentagem de pessoas } \\
\text { insatisfeitas segundo } \\
\text { os votos }(\boldsymbol{\%})\end{array}$ & $\begin{array}{c}\text { Diferença } \\
(\boldsymbol{\%})\end{array}$ \\
\hline Sala TR & $-0,08$ & $-0,22$ & 0,14 & 6,2 & $\begin{array}{c}6,5(2 \text { por frio } \\
\text { e 1 por calor })\end{array}$ & 0,3 \\
\hline
\end{tabular}

Figura 16 - Votos relativos ao conforto térmico (CT)

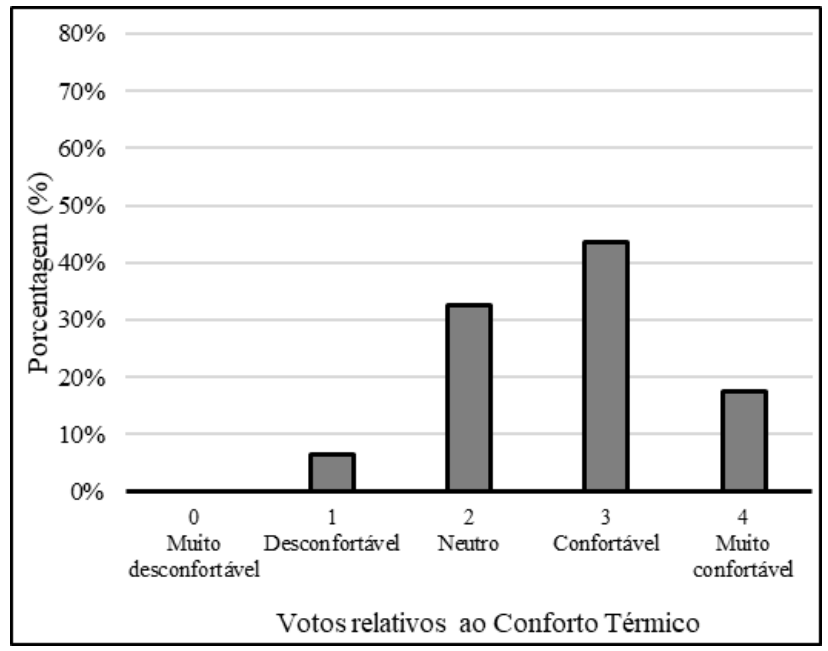

Figura 17 - Temperaturas operativas vs. votos relativos ao conforto térmico (CT)

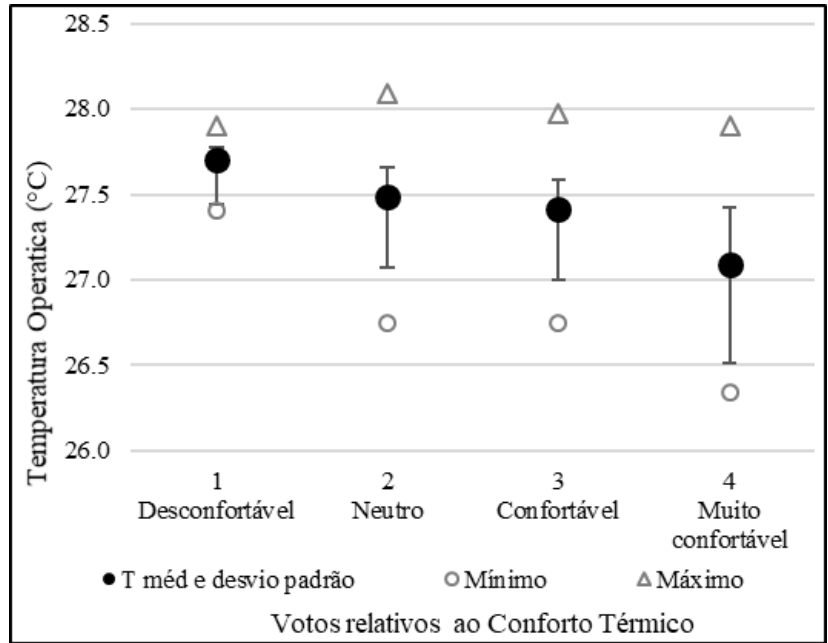


Figura 18 - Votos relativos à preferência térmica (PT)

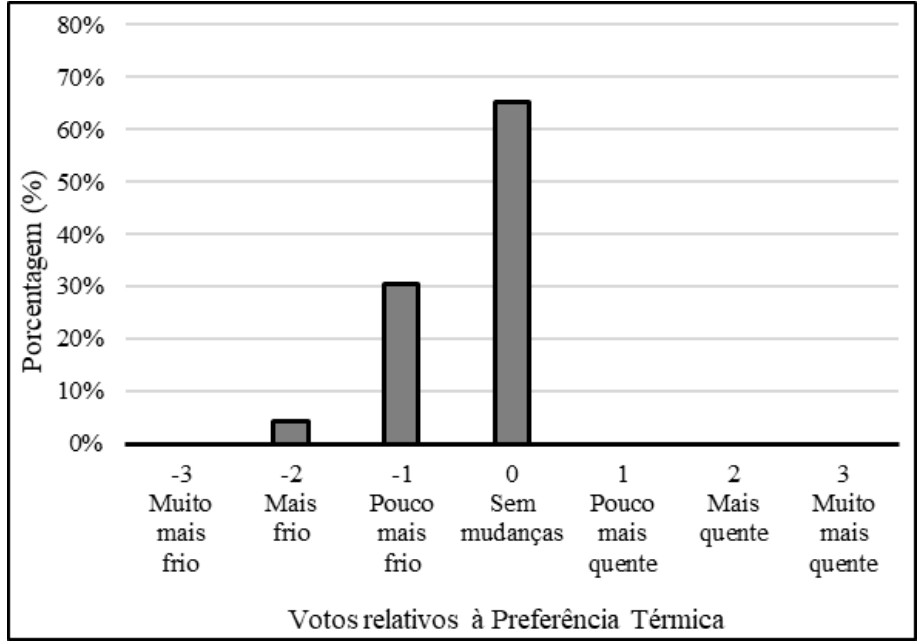

Tian e Love (2008) realizaram um estudo com ambientes resfriados por tubos embutidos na laje de piso e teto, utilizando sistema classificado como "TABS" (thermally activated building systems) (LEHMANN; DORER; KOSCHENZ, 2007) tendo água como meio fluido, com 58 indivíduos avaliando o sistema sob condições de verão. Verificaram que as discrepâncias entre respostas subjetivas e dados estimados de conforto pelo PMV foram muito pequenas. Humphreys e Nicol (2002) comprovam, a partir de uma amostra de mais de 2.000 respostas térmicas, que em ambientes naturalmente ventilados, excetuando determinada faixa de conforto (com temperaturas operativas entre $20{ }^{\circ} \mathrm{C}$ e $26{ }^{\circ} \mathrm{C}$ ), as discrepâncias se tornavam maiores ou menores, em função da temperatura operativa ser mais alta ou mais baixa, respectivamente, que a faixa preferencial. Ressalte-se que, no caso do presente estudo, tendo-se observado respostas térmicas na faixa de conforto apenas, variando entre valores de PMV entre -0,57 e 0,20, não é possível afirmar que o modelo PMV se aplique a situações de calor e frio no ambiente estudado.

Para além do fato de que foram registradas temperaturas internas do ar amenas (Figuras 11, 13 e 14) durante as sessões (entre $25,8^{\circ} \mathrm{C}$ e $28,8^{\circ} \mathrm{C}$ ), o alto índice de satisfação dos voluntários com as condições ambientais providas pelo sistema também pode ser explicado pelas temperaturas radiantes médias com valores inferiores aos das temperaturas do ar (Figura 9), efeito potencializado pelo fato de que $65 \%$ dos voluntários utilizaram vestimenta com baixo isolamento (entre 0,23 e 0,29 clo). Conforme Szokolay (2008), em climas quentes, nos quais predomina o uso de roupas leves, as temperaturas radiantes médias apresentam peso duas vezes maior que a temperatura do ar na percepção térmica dos usuários.

Em se tratando dos modelos adaptativos, o modelo europeu foi mais compatível com os votos declarados pelos participantes. Segundo a EN 15251 (EUROPEAN..., 2007), a temperatura neutra para o período foi $27,7^{\circ} \mathrm{C}$, próxima das temperaturas operativas médias, quando a ST declarada era "neutralidade" $\left(27,3{ }^{\circ} \mathrm{C}\right)$, quando o voto quanto ao CT era "confortável" $\left(27,4{ }^{\circ} \mathrm{C}\right)$ e quando a PT era "sem mudanças" $\left(27,3{ }^{\circ} \mathrm{C}\right)$. Segundo a ASHRAE, no período, a média das temperaturas neutras seria $26,2{ }^{\circ} \mathrm{C}$. Aparentemente, os usuários tolerariam temperaturas operativas um pouco acima dos limites propostos pela Standard 55 (AMERICAN..., 2017).

Por outro lado, modelos adaptativos, como o modelo europeu e o proposto pela Standard 55, investigados neste artigo quanto às respostas térmicas reais, são direcionados a condições nas quais modelos de balanço de energia não são suficientes para descrever sensação e satisfação térmica (DE DEAR; BRAGER, 2002). Segundo esses autores, modelos adaptativos são aplicáveis a ambientes naturalmente ventilados, ou seja, que se apoiam na ventilação natural e uso de aberturas. Embora tenha havido no presente estudo de concordância entre votos reportados em conforto e as faixas de neutralidade térmica obtidas pelo procedimento da EN 15251 e da Standard 55, o ambiente testado não é caracterizado como naturalmente ventilado, estando mais próximo em termos térmicos de ambientes climatizados, com maior constância térmica interna (BRAGER; DE DEAR, 1998). Em vista disso, a distinção apresentada por Brager e de Dear (1998) entre respostas térmicas subjetivas em ambientes condicionados artificialmente (por equipamento de ar-condicionado) e naturalmente ventilados, no caso do sistema TR acoplado a resfriamento radiante aqui estudado, é discutível. Porém, em razão da faixa de condições de conforto obtida no estudo de campo ser restrita a valores 
próximos às condições de confortabilidade e neutralidade térmica, não permitem avaliar a adequação dos modelos de conforto para regiões acima ou abaixo dessa faixa.

\section{Conclusões}

Comparativamente ao desempenho térmico da configuração original da edificação-teste, no período aqui abordado, a instalação dos painéis radiantes acoplados ao teto-reservatório resultou em redução de aproximadamente $2{ }^{\circ} \mathrm{C}$ na média das temperaturas internas do ar. Esse valor é próximo aos obtidos em experimentos com células-teste em Sde Boqer (GIVONI, 1984), Florianópolis (GONZÁLEZ-CRUZ et al., 2014) e Curitiba (LANGE, 2016).

Quanto ao objetivo principal do estudo, os votos dos voluntários em relação à sensação térmica, conforto térmico e preferência térmica indicaram satisfação com o ambiente térmico. Os painéis radiantes associados ao teto-reservatório foram efetivos em propiciar condições ambientais adequadas aos voluntários na edificação-teste, a despeito das condições ambientais externas (verão em clima desértico).

Quanto ao objetivo secundário, o modelo adaptativo dado pela EN 15251 (EUROPEAN..., 2007) foi o mais compatível com os votos declarados pelos participantes. Também houve concordância com o modelo PMV/PPD. Embora a amostra utilizada no experimento seja relativamente pequena, chama atenção a maior compatibilidade com o modelo dado pela EN-15.251, pois, no Brasil, a análise de dados de experimentos sobre percepção térmica (PEREIRA; ASSIS, 2014) tem revelado mais compatibilidade com modelos adaptativos próximos do indicado pela norma Standard 55 (AMERICAN..., 2017). Essa diferença aponta para a necessidade de cuidado com as generalizações. Previamente à adoção de um modelo adaptativo, é importante que tenham sido realizados levantamentos de percepção térmica locais, contemplando o maior número possível de contextos populacionais e climáticos.

Observou-se ainda que o gradiente térmico observado na sala TR, devido ao teto mais frio, não foi fator de desconforto e, de acordo com a literatura, poderia ser aumentado sem gerar prejuízos aos voluntários (FANGER et al., 1985).

Em se tratando de estudos futuros, sugerem-se estudos para aplicação e monitoramento de painéis radiantes acoplados a TR em uma edificação ou célula-teste de grande porte em clima brasileiro. Um experimento local e de longo prazo trará mais informações sobre a aplicabilidade do sistema às edificações brasileiras.

\section{Referências}

AMERICAN SOCIETY OF HEATING, REFRIGERATING, AND AIR-CONDITIONING ENGINEERS. Standard 55: thermal environmental conditions for human occupancy. Atlanta, 2017.

AMERICAN SOCIETY OF HEATING, REFRIGERATING, AND AIR-CONDITIONING ENGINEERS. Standard 55: thermal environmental conditions for human occupancy. Atlanta, 2010.

AMERICAN SOCIETY OF HEATING, REFRIGERATING, AND AIR-CONDITIONING ENGINEERS.

Standard 55: thermal environmental conditions for human occupancy. Atlanta, 2013.

AMERICAN SOCIETY OF HEATING, REFRIGERATING, AND AIR-CONDITIONING ENGINEERS. 2012 ASHRAE Handbook: heating, ventilating, and air-conditioning: systems and equipment. Atlanta: 2012.

AUliCIEMS, A.; SZOKOLAY, S. V. Thermal comfort. PLEA Notes, v. 3, 2007.

BRAGER, G. S.; DE DEAR, R. J. Thermal adaptation in the built environment: a literature review. Energy and Buildings, v. 27, n. 1, p. 83-96, 1998.

BRAVO, G.; GONZÁLEZ, E. Thermal comfort in naturally ventilated spaces and under indirect evaporative passive cooling conditions in hot-humid climate. Energy and Buildings, v. 63, p. 79-86, 2013.

CHÁVEZ, J. R. G.; GIVONI, B.; MUNDET, S. Cooling by roof pond with floating insulation in the hot humid climate of Veracruz, Mexico. In: INTERNATIONAL CONFERENCE ON PASSIVE AND LOW ENERGY ARCHITECTURE, 24., Singapore, 2007. Proceedings [...] Singapore, 2007.

DANESHVAR, M. R. M.; BAGHERZADEH, A.; TAVOUSI, T. Assessment of bioclimatic comfort conditions based on Physiologically Equivalent Temperature (PET) using the RayMan Model in Iran. Central European Journal of Geosciences, v. 5, n. 1, p. 53-60, 2013. 
DE DEAR, R. J.; BRAGER, G. S. COOPER, D. Developing an adaptive model of thermal comfort and preference: final report ASHRAE RP-884. Sydney, 1997.

DE DEAR, R. J.; BRAGER, G. S. Thermal comfort in naturally ventilated buildings: revisions to ASHRAE Standard 55. Energy and Buildings, v. 34, n. 6, p. 549-561, 2002.

ERELL, E. et al. A passive cooling laboratory building for hot-arid zones. In: INTERNATIONAL CONFERENCE- ENERGY AND BUILDING IN MEDITERRANEAN AREA, 3., Thessaloniki, 1992. Proceedings [...] Thessaloniki, 1992.

ERELL, E.; ETZION, Y. Analysis and experimental verification of an improved cooling radiator. Renewable Energy, v. 16, p. 700-703, 1999.

EUROPEAN COMMITTEE FOR STANDARDIZATION. EN 15251: indoor environmental input parameters for design and assessment of energy performance of buildings addressing indoor air quality, thermal environment, lighting and acoustics. Brussels, 2007.

FANGER, P. O. et al. Comfort limits for asymmetric thermal radiation. Energy and Buildings, v. 8, n. 3, p. 225-236, 1985.

FERNÁNDEZ-GONZÁLEZ, A.; COSTACHE, F. I. Cooling Performance of a Wet Roofpond System in Las Vegas, Nevada. In: WORLD RENEWABLE ENERGY FORUM, Denver, 2012. Proceedings [...] Denver: C. Fellows, 2012.

FOUNTAIN, M. E.; HUIZENGA, C. WinComf: A Windows 3.1 Thermal Sensation Model - User's Manual. Berkeley: Environmental Analytics, 1996.

GIVONI, B. Indoor temperature reduction by passive cooling systems. Solar Energy, v. 85, n. 8, p. 16921726, 2011.

GIVONI, B. Options and applications of passive cooling. Energy and Buildings, v. 7, n. 4, p. 297-300, 1984.

GONZÁLEZ-CRUZ, E. M. Estude de materiaux et de techniques du batiment pour la conception architecturale bioclimatique en climat chaud et humide. Paris, 1997. 196 f. Tese - Ecole des Mines de Paris, Paris, 1997.

GONZÁLEZ-CRUZ, E. M. et al. Estudo experimental com sistemas de resfriamento passivo em Florianópolis. In: ENCONTRO NACIONAL DE TECNOLOGIA DO AMBIENTE CONSTRUÍDO, 15. Maceió, 2014. Anais [...] Maceió: ANTAC, 2014.

GONZÁLEZ-CRUZ, E. M.; GONZÁLEZ-GARCIA, S. I. Estudio experimental sobre el comportamiento térmico de un nuevo tipo de techo-estanque para el enfriamiento pasivo en clima húmedo. Ambiente Construído, Porto Alegre, v. 13, n. 4, p. 149-171, out./dez. 2013.

GONZÁLEZ-CRUZ, E. M.; KRÜGER, E. L.; GIORDANO, D. E. Estudo da aplicabilidade de um sistema de resfriamento evaporativo indireto para otimização do conforto térmico em residências no território brasileiro. In: ENCONTRO NACIONAL DE TECNOLOGIA DO AMBIENTE CONSTRUÍDO, 15. Maceió, 2014. Anais [...] Maceió: ANTAC, 2014.

HOYT, T. et al. CBE Thermal Comfort Tool. Berkeley: Center for the Built Environment, University of California Berkeley, 2017. Disponível em: http://comfort.cbe.berkeley.edu/. Acesso em: 20 maio 2017.

HUMPHREYS, M. A.; NICOL, J. F.. The validity of ISO-PMV for predicting comfort votes in every-day thermal environments. Energy and buildings, v. 34, n. 6, p. 667-684, 2002.

IMANARI, T.; OMORI, T.; BOGAKI, K. Thermal comfort and energy consumption of the radiant ceiling panel system: Comparison with the conventional all-air system. Energy and buildings, v. 30, n. 2, p. 167$175,1999$.

INSTITUTO NACIONAL DE METROLOGIA, NORMALIZAÇÃO E. QUALIDADE INDUSTRIAL. Portaria 449: regulamento Técnico da Qualidade para o Nível de Eficiência Energética das Edificações Residenciais. Rio de Janeiro, 2010.

INTERNATIONAL ORGANIZATION FOR STANDARDIZATION. ISO 10551: ergonomics of the thermal environment: assessment of the influence of the thermal environment using subjective judgement scales Ergonomie. Gèneve, 1995. 
INTERNATIONAL ORGANIZATION FOR STANDARDIZATION. ISO 7726: ergonomics of the thermal environment: instruments for measuring physical quantities. Geneve, 1998.

INTERNATIONAL ORGANIZATION FOR STANDARDIZATION. ISO 7730: ergonomics of the thermal environment: analytical determination and interpretation of thermal comfort using calculation of the PMV and PPD indices and local thermal comfort criteria. Gèneve, 2005.

ISRAEL METEOROLOGICAL SERVICE. Climate information. Bet-Dagan: IMS, 2007. Disponível em: http://www.ims.gov.il. Acesso em: 15 set. 2017.

ISRAEL METEOROLOGICAL SERVICE. Rainfall normals for the period 1981-2010. Bet-Dagan: IMS, 2012. Disponível em: http:// http://www.ims.gov.il/IMSEng/CLIMATE/LongTermRain/. Acesso em: 15 set. 2017.

KARMANN, C.; SCHIAVON, S.; BAUMAN, F. Thermal comfort in buildings using radiant vs. all-air systems: a critical literature review. Building and Environment, v. 111, p. 123-131, 2017.

KOTTEK, M. et al. World map of the Köppen-Geiger climate classification updated. Meteorologische Zeitschrift, v. 15, n. 3, p. 259-263, 2006.

KRÜGER, E. et al. Short-term acclimatization effects in an outdoor comfort study. In: INTERNATIONAL CONFERENCE ON URBAN CLIMATE, 9., France, 2015. Proceedings [...] France, 2015.

KRÜGER, E. et al. Avaliação do potencial de resfriamento de um sistema teto-reservatório para condições subtropicais. Ambiente Construído, Porto Alegre, v. 16, n. 3, p. 107-125, jul./set. 2016.

KRÜGER, E. et al. Comparing occupant thermal perception of air conditioning and ceiling- mounted radiant cooling panels coupled to a roof pond. In: WINDSOR CONFERENCE: RETHINKING COMFORT, Windsor, 2018. Proceedings [...] Windsor, 2018.

KRÜGER, E. et al. Proposition of a simplified method for predicting hourly indoor temperatures in test cells. Ambiente Construído, Porto Alegre, v. 17, n. 3, p. 57-70, jul./set. 2017.

KRÜGER, E. GONZÁLEZ-CRUZ, E.; GIVONI, B. Effectiveness of indirect evaporative cooling and thermal mass in a hot arid climate. Building and Environment, v. 45, n. 6, p. 1422-1433, 2010.

KRÜGER, E.; FERNANDES, L.; LANGE, S. Thermal performance of different configurations of a roof pond-based system for subtropical conditions. Building and Environment, v. 107, p. 90-98, 2016.

LAMBERTS, R. Heat transfer through roofs of low cost Brazilian houses. 1988. Thesis - University of Leeds, 1988.

LANGE, S. C. sistema passivo de resfriamento: estudo de um teto reservatório no clima de Curitiba localizado na zona bioclimática 1. Curitiba, 2016. Dissertação (Programa de Pós-Graduação em Tecnologia e Sociedade) - Universidade Tecnológica Federal do Paraná, Curitiba, 2016.

LEHMANN, B.; DORER, V.; KOSCHENZ, M. Application range of thermally activated building systems tabs. Energy and Buildings, v. 39, n. 5, p. 593-598, 2007.

LI, R. et al. Field evaluation of performance of radiant heating/cooling ceiling panel system. Energy and Buildings, v. 86, p. 58-65, 2015.

LOVEDAY, D. L. et al. Designing for thermal comfort in combined chilled ceiling/displacement ventilation environments. Transactions-American Society of Heating Refrigerating and Air Conditioning Engineers, v. 104, p. 901-911, 1998.

MEGGERS, F. et al. The thermoheliodome: "Air conditioning" without conditioning the air, using radiant cooling and indirect evaporation. Energy and Buildings, v. 157, p. 11-19, 2017.

MIRIEL, J.; SERRES, L.; TROMBE, A. Radiant ceiling panel heating-cooling systems: Experimental and simulated study of the performances, thermal comfort and energy consumptions. Applied Thermal Engineering, v. 22, n. 16, p. 1861-1873, 2002.

MUSTAKALLIO, P. et al. Thermal environment in a simulated double office room with convective and radiant cooling systems. Building and Environment, v. 123, p. 88-100, 2017.

NICOL, F.; WILSON, M. An overview of the European Standard EN 15251. In: WINDSOR CONFERENCE 2010: ADAPTING TO CHANGE: NEW THINKING ON COMFORT, 6., Windsor, 2010. Proceedings [...] London: Network for Comfort and Energy Use in Buildings, 2010. 
PEREIRA, I. M.; ASSIS, E. S. de. Avaliação de modelos de índices adaptativos para uso no projeto arquitetônico bioclimático. Ambiente Construído, Porto Alegre, v. 10, n. 1, p. 31-51, jan./mar. 2014.

ROMANA, F. et al. On the measurement of the mean radiant temperature and its influence on the indoor thermal environment assessment. Building and Environment, v. 63, p. 79-88, 2013.

RUBEL, F. et al. The climate of the European Alps: shift of very high resolution Köppen-Geiger climate zones 1800-2100. Meteorologische Zeitschrift, v. 26, n. 2, p. 115-125, 2017.

RUNSHENG, T.; ETZION, Y.; ERELL, E. Experimental studies on a novel roof pond configuration for the cooling of buildings. Renewable Energy, v. 28, n. 10, p. 1513-1522, 2003.

SHARIFI, A.; YAMAGATA, Y. Roof ponds as passive heating and cooling systems: a systematic review. Applied Energy, v. 160, p. 336-357, 2015.

SOLDOVIERI, T.; VILORIA, T. El Angulo Sólido y algunas de sus aplicaciones. Maracaibo: Universidad del Zulia, 2016.

SPANAKI, A.; TSOUTSOS, T.; KOLOKOTSA, D. On the selection and design of the proper roof pond variant for passive cooling purposes. Renewable and Sustainable Energy Reviews, v. 15, n. 8, p. 3523 3533, 2011.

SZOKOLAY, S. Introduction to Architectural science: the basis of sustainable design. $2^{\text {nd. }}$ ed. Oxford: Elsevier, 2008.

TÉPOX, J. E. V.; GONZÁLEZ-CRUZ, E. M.; MATA, M. F. E. Cubiertas y estanques para optimizar el sistema pasivo de techo estanque metálico en clima cálido seco extremo : estudio experimental exploratorio. Palapa, v. 3, p. 43-54, 2008.

TIAN, Z.; LOVE, J. A. A field study of occupant thermal comfort and thermal environments with radiant slab cooling. Building and Environment, v. 43, n. 10, p. 1658-1670, 2008.

TIWARI, G. N.; KUMAR, A.; SODHA, M. S. A Review - Cooling by water evaporation over roof. Energy Conversion and Management, v. 22, n. 2, p. 143-153, 1982.

WORLD HEALTH ORGANIZATION. Physical status: the use and interpretation of anthropometry. Report of a WHO Expert Committee. Geneva, 1995.

\section{Agradecimentos}

Agradecimentos: ao Swiss Institute for Dryland Environmental \& Energy Research (SIDEER), Ben-Gurion University of the Negev, campus Sde Boqer, pela seção dos dados relativos ao ambiente externo; ao Bona Terra Department of Man in the Desert, Ben-Gurion University of the Negev, campus Sde Boqer, pelo empréstimo dos equipamentos e da edificação-teste; e à Coordenação de Aperfeiçoamento de Pessoal de Nível Superior (Capes), pelo apoio a esta pesquisa.

\section{Leandro Carlos Fernandes}

Programa de Pós-Graduação em Engenharia de Construção Civil | Universidade Federal do Paraná | Rua Cel. Francisco H. dos Santos, 100 , $4^{\circ}$ andar, Jardim das Américas | Curitiba - PR - Brasil | CEP 81531-980 | Tel.: (41) 3361-3462 | E-mail: fernandes.ufpr@gmail.com

\section{Eduardo Leite Krüger}

Programa de Pós-Graduação em Engenharia Civil | Universidade Tecnológica Federal do Paraná | Av. Deputado Heitor de Alencar Furtado, 5000, Ecoville, Campus Curitiba - Sede Ecoville | Curitiba - PR - Brasil | CEP 81280-340 | Tel.: (41) 3279-4578 | E-mail: ekruger@utfpr.edu.br

\section{Wolfgang Motzafi-Haller}

Ben Gurion University of the Negev | Midreshet Ben Gurion, Israel | E-mail: womoha@post.bgu.ac.il

\section{Ambiente Construído}

Revista da Associação Nacional de Tecnologia do Ambiente Construído

Av. Osvaldo Aranha, $99-3^{\circ}$ andar, Centro

Porto Alegre - RS - Brasil CEP $90035-190$

Telefone: +55 (51) 3308-4084

Fax: +55 (51) 3308-4054

www.seer.ufrgs.br/ambienteconstruido

E-mail: ambienteconstruido@ufrgs.br 